NBER WORKING PAPER SERIES

\title{
EMPIRICAL EXCHANGE RATE MODELS \\ OF THE NINETIES: \\ ARE ANY FIT TO SURVIVE?
}

\author{
Yin-Wong Cheung \\ Menzie D. Chinn \\ Antonio Garcia Pascual
}

Working Paper 9393

http://www.nber.org/papers/w9393

\section{NATIONAL BUREAU OF ECONOMIC RESEARCH \\ 1050 Massachusetts Avenue \\ Cambridge, MA 02138}

December 2002

\begin{abstract}
We thank, without implicating, Jeff Frankel, Fabio Ghironi, Jan Groen, Lutz Kilian, Ed Leamer, Ronald MacDonald, David Papell, John Rogers, Lucio Sarno, Torsten Sløk, Frank Westermann, seminar participants at Academica Sinica, Boston College, UCLA, University of Houston and conference participants at CES-ifo Venice Summer Institute conference on "Exchange Rate Modeling" for helpful comments, and Jeannine Bailliu, Gabriele Galati and Guy Meredith for providing data. The financial support of faculty research funds of the University of California, Santa Cruz is gratefully acknowledged. The views expressed herein are those of the authors and not necessarily those of the International Monetary Fund or the National Bureau of Economic Research.
\end{abstract}

(C) 2002 by Yin-Wong Cheung, Menzie D. Chinn, and Antonio Garcia Pascual. All rights reserved. Short sections of text not to exceed two paragraphs, may be quoted without explicit permission provided that full credit including, (C) notice, is given to the source. 
Empirical Exchange Rate Models of the Nineties:

Are Any Fit to Survive?

Yin-Wong Cheung, Menzie D. Chinn, and Antonio Garcia Pascual

NBER Working Paper No. 9393

December 2002

JEL No. F31, F47

\begin{abstract}
Previous assessments of nominal exchange rate determination have focused upon a narrow set of models typically of the 1970's vintage. The canonical papers in this literature are by Meese and Rogoff $(1983,1988)$, who examined monetary and portfolio balance models. Succeeding works by Mark (1995) and Chinn and Meese (1995) focused on similar models. In this paper we re-assess exchange rate prediction using a wider set of models that have been proposed in the last decade: interest rate parity, productivity based models, and "behavioral equilibrium exchange rate" models. The performance of these models is compared against a benchmark model - the Dornbusch-Frankel sticky price monetary model. The models are estimated in error correction and first-difference specifications. Rather than estimating the cointegrating vector over the entire sample and treating it as part of the ex ante information set as is commonly done in the literature, we recursively update the cointegrating vector, thereby generating true ex ante forecasts. We examine model performance at various forecast horizons (1 quarter, 4 quarters, 20 quarters) using differing metrics (mean squared error, direction of change), as well as the "consistency" test of Cheung and Chinn (1998). No model consistently outperforms a random walk, by a mean squared error measure; however, along a direction-of-change dimension, certain structural models do outperform a random walk with statistical significance. Moreover, one finds that these forecasts are cointegrated with the actual values of exchange rates, although in a large number of cases, the elasticity of the forecasts with respect to the actual values is different from unity. Overall, model/specification/currency combinations that work well in one period will not necessarily work well in another period.
\end{abstract}

\author{
Yin-Wong Cheung \\ Department of Economics \\ University of California \\ Santa Cruz, CA 95064 \\ cheung@cats.ucsc.edu
}

\author{
Menzie D. Chinn \\ Department of Economics \\ University of California \\ Santa Cruz, CA 95064 \\ and NBER \\ chinn@cats.ucsc.edu
}

\author{
Antonio Garcia Pascual \\ International Monetary Fund \\ $70019^{\text {th }}$ Street, NW \\ Washington, DC 20431 \\ agarciapascual@imf.org
}




\section{Introduction}

The recent movements in the dollar and the euro have appeared seemingly inexplicable in the context of standard models. While the dollar may not have been "dazzling" - as it was described in the mid-1980's - it has been characterized as overly "darling."1 And the euro's ability to repeatedly confound predictions needs little re-emphasizing.

It is against this backdrop that several new models have been forwarded in the past decade. Some explanations are motivated by new findings in the empirical literature, such the correlation between net foreign asset positions and real exchange rates. Others, such as those based on productivity differences, are solidly grounded in the theoretical literature. None of these models, however, have been subjected to rigorous examination of the sort that Meese and Rogoff conducted in their seminal work, the original title of which we have appropriated and amended for this study. ${ }^{2}$

We believe that a systematic examination of these newer empirical models is long overdue, for a number of reasons. First, while these models have become prominent in policy and financial circles, they have not been subjected to the sort of rigorous out-of-sample testing conducted in academic studies. For instance, behavioral equilibrium exchange rate models essentially combinations of real interest differential, productivity and portfolio balance models have been used in estimating the "equilibrium" values of the dollar and the euro. ${ }^{3}$

Second, most of the recent academic treatments exchange rate forecasting performance rely upon a single model - such as the monetary model - or some other limited set of models of 1970's vintage. Thus, in the recent Journal of International Economics symposium celebrating the $20^{\text {th }}$ anniversary of the Meese-Rogoff papers, the nominal exchange rate approaches applied

\footnotetext{
${ }^{1}$ Frankel (1985) and The Economist (2001), respectively.
}

${ }^{2}$ Meese and Rogoff (1983) was based upon work in "Empirical exchange rate models of the seventies: are any fit to survive?" International Finance Discussion Paper No. 184 (Board of Governors of the Federal Reserve System, 1981).

${ }^{3}$ For the euro: Morgan Stanley (Fels and Yilmaz, 2001), Bundesbank (Clostermann and Schnatz, 2000), ECB ( Maeso-Fernandez et al., 2001), and IMF (Alberola, et al., 1999). For the dollar: Morgan Stanley (Yilmaz and Jen, 2001). 
to the G-3 currencies included the flexible price monetary model, purchasing power parity, and the interest differential.

Third, the same criteria are often used, neglecting many alternative dimensions of model forecast performance. That is, the first and second moment metrics such as mean error and mean squared error are considered, while other aspects that might be of greater importance are often neglected. We have in mind the direction of change - perhaps more important from a market timing perspective - and other indicators of forecast attributes.

In this study, we extend the forecast comparison of exchange rate models in several dimensions.

- Four models are compared against the random walk. Only one of the structural models - the benchmark sticky-price monetary model of Dornbusch and Frankel - has been the subject of previous systematic analyses. The other models include one incorporating productivity differentials in a fashion consistent with a Balassa-Samuelson formulation, an interest rate parity specification, and a representative behavioral equilibrium exchange rate model.

- The behavior of US dollar-based exchange rates of the Canadian dollar, British pound, Deutsche mark and Japanese yen are examined. We also examine the corresponding yenbased rates, to insure that our conclusions are not driven by dollar specific results.

- The models are estimated in two ways: in first-difference and error correction specifications.

- Forecasting performance is evaluated at several horizons (1-, 4- and 20-quarter horizons) and two sample periods (post-Louvre Accord and post-1982).

- We augment the conventional metrics with a direction of change statistic and the “consistency" criterion of Cheung and Chinn (1998).

In accord with previous studies, we find that no model consistently outperforms a random walk according to the mean squared error criterion at short horizons. Somewhat at variance with some previous findings, we find that the proportion of times the structural models incorporating long-run relationships outperform a random walk at long horizons is slightly less than would be expected if the outcomes were merely random.

On the other hand, the direction-of-change statistics indicate that the structural models do outperform a random walk characterization by a statistically significant amount. For instance, 
using a $10 \%$ significance level, the sticky price model outperforms a random walk $23 \%$ of the time for dollar-based exchange rates. For yen based exchange rates, the interest rate parity model outperforms a random walk $37 \%$ of the time.

In terms of the "consistency" test of Cheung and Chinn (1998), similarly positive results are obtained. The actual and forecasted rates are cointegrated more often than would occur by chance for all the models. While in many of these cases of cointegration, the condition of unitary elasticity of expectations is rejected, between $12 \%$ to $13 \%$ fulfill all the conditions of the consistency criteria.

We conclude that the question of exchange rate predictability remains unresolved. In particular, while the oft-used mean squared error criterion provides a dismal perspective, criteria other than the conventional ones suggest that structural exchange rate models have some usefulness. Furthermore, the best model and specification tend to be specific to the currency and out-of-sample forecasting period.

\section{Theoretical Models}

The universe of empirical models that have been examined over the floating rate period is enormous. Consequently any evaluation of these models must necessarily be selective. Our criteria require that the models are (1) prominent in the economic and policy literature, (2) readily implementable and replicable, and (3) not previously evaluated in a systematic fashion. We use the random walk model as our benchmark naive model, in line with previous work, but we also select one workhorse model, the basic Dornbusch (1976) and Frankel (1979) model as a comparator specification, as it still provides the fundamental intuition for how flexible exchange rates behave. The sticky price monetary model can be expressed as follows:

$$
s_{t}=\beta_{0}+\beta_{1} \hat{m}_{t}+\beta_{2} \hat{y}_{t}+\beta_{3} \hat{i}_{t}+\beta_{4} \hat{\pi}_{t}+u_{t},
$$

where $m$ is $\log$ money, $y$ is $\log$ real GDP, $i$ and $\pi$ are the interest and inflation rate, respectively, "^" denotes the intercountry difference, and $u_{t}$ is an error term.

The characteristics of this model are well known, so we will not devote time to discussing the theory behind the equation. We will observe, however, that the list of variables included in (1) encompasses those employed in the flexible price version of the monetary model, 
as well as the micro-based general equilibrium models of Stockman (1980) and Lucas (1982).

Second, we assess models that are in the Balassa-Samuelson vein, in that they accord a central role to productivity differentials to explaining movements in real, and hence also nominal, exchange rates. Real versions of the model can be traced to DeGregorio and Wolf (1994), while nominal versions include Clements and Frenkel (1980) and Chinn (1997). Such models drop the purchasing power parity assumption for broad price indices, and allow the real exchange rate to depend upon the relative price of nontradables, itself a function of productivity $(z)$ differentials. A generic productivity differential exchange rate equation is

$$
s_{t}=\beta_{0}+\beta_{1} \hat{m}+\beta_{2} \hat{y}+\beta_{3} \hat{i}+\beta_{5} \hat{z}_{t}+u_{t} .
$$

The third set of models we examine includes the behavioral equilibrium exchange rate models. This is a diverse set of models that incorporate a number of familiar and unfamiliar relationships. A typical specification is:

$$
s_{t}=\beta_{0}+\hat{p}_{t}+\beta_{5} \hat{\omega}_{t}+\beta_{6} \hat{r}_{t}+\beta_{7} \hat{g}_{e b t}+\beta_{8} t_{o t}+\beta_{9} n f a_{t}+u_{t},
$$

where $p$ is the log price level (CPI), $\omega$ is the relative price of nontradables, $r$ is the real interest rate, gdebt the government debt to GDP ratio, tot the log terms of trade, and $n f a$ is the net foreign asset. This specification can be thought of as incorporating the Balassa-Samuelson effect, the real interest differential model, an exchange risk premium associated with government debt stocks, and additional portfolio balance effects arising from the net foreign asset position of the economy. ${ }^{4}$ Clark and MacDonald (1999) is a recent exposition of this approach.

Models based upon this framework have been the predominant approach to determining the rate at which currencies will gravitate to over some intermediate horizon, especially in the context of policy issues. For instance, the behavioral equilibrium exchange rate approach is the model that is most used to determine the long-term value of the euro. ${ }^{5}$

${ }^{4}$ On this latter channel, Cavallo and Ghironi (2002) provide a role for net foreign assets in the determination of exchange rates in the sticky-price optimizing framework of Obstfeld and Rogoff (1995).

${ }^{5}$ We do not examine two closely related approaches: the internal-external balance approach of the IMF (see Faruqee, Isard and Masson, 1999) and the NATREX approach (Stein, 1999). The IMF approach requires extensive judgements regarding the trend level of output, and the impact of demographic variables upon various macroeconomic aggregates. We did not 
The final specification assessed is not a model per se; rather it is an arbitrage relationship - uncovered interest rate parity:

$$
s_{t+k}=s_{t}+\hat{i}_{t, k}
$$

where $i_{t, k}$ is the interest rate of maturity $k$. Unlike the other specifications, this relation need not be estimated in order to generate predictions.

Interest rate parity at long horizons has recently gathered empirical support (Alexius, 2001 and Meredith and Chinn, 1998), in contrast to the disappointing results at the shorter horizons. MacDonald and Nagayasu (2000) have also demonstrated that long-run interest rates appear to predict exchange rate levels. On the basis of these findings, we anticipate that this specification will perform better at the longer horizons than at shorter. ${ }^{6}$

\section{Data, Estimation and Forecasting Comparison}

\subsection{Data}

The analysis uses quarterly data for the United States, Canada, UK, Japan, Germany, and Switzerland over the $1973 \mathrm{q} 2$ to $2000 \mathrm{q} 4$ period. The exchange rate, money, price and income variables are drawn primarily from the IMF's International Financial Statistics. The productivity data were obtained from the Bank for International Settlements, while the interest rates used to conduct the interest rate parity forecasts are essentially the same as those used in Meredith and Chinn (1998)). See the Data Appendix for a more detailed description.

Two out-of-sample periods are used to assess model performance: 1987q2-2000q4 and 1983q1-2000q4. The former period conforms to the post-Louvre Accord period, while the latter spans the period after the end of monetary targeting in the U.S. Figures 1 and 2 depict, respectively, the dollar based Deutschemark and yen exchange rates, with the right-most line

believe it would be possible to subject this methodology to the same out of sample forecasting exercise applied to the others. The NATREX approach is conceptually different from the BEER methodology. However, it shares a sufficiently large number of attributes with the latter that we decided not to separately examine it.

${ }^{6}$ Despite this finding, there is little evidence that long term interest rate differentials - or equivalently long-dated forward rates - have been used for forecasting at the horizons we are investigating. One exception from the non-academic literature is Rosenberg (2001). 
indicating the beginning of the first out-of-sample period, and the left-most line indicating the second. The shorter out-of-sample period (1987-2000) spans a period of relative dollar stability (and appreciation in the case of the mark). The longer out-of-sample period subjects the models to a more rigorous test, in that the prediction takes place over a large dollar appreciation and subsequent depreciation (against the mark) and a large dollar depreciation (from 250 to 150 yen per dollar). In other words, this longer span encompasses more than one "dollar cycle." The use of this long out-of-sample forecasting period has the added advantage that it ensures that there are many forecast observations to conduct inference upon. ${ }^{7}$

\subsection{Estimation and Forecasting}

We adopt the convention in the empirical exchange rate modeling literature of implementing "rolling regressions." That is, estimates are applied over a given data sample, outof-sample forecasts produced, then the sample is moved up, or "rolled" forward one observation before the procedure is repeated. This process continues until all the out-of-sample observations are exhausted. This procedure is selected over recursive estimation because it is more in line with previous work, including the original Meese and Rogoff paper. Moreover, the power of the test is kept constant as the sample size over which estimation occurs is fixed, rather than increasing as it does in the recursive framework.

Two specifications of these theoretical models were estimated: (1) an error correction specification, and (2) a first differences specification. Since implementation of the error correction specification is relatively involved, we will address the first-difference specification to begin with. Consider the general expression for the relationship between the exchange rate and fundamentals:

$$
s_{t}=X_{t} \Gamma+u_{t},
$$

${ }^{7}$ We are aware of the debate over the use of out of sample versus in sample tests. Out of sample tests have been favored as a means of guarding against data mining. Inoue and Kilian (2002) argue that in sample tests often have higher power than out of sample, even after accounting for the effects of data mining. We retain the use of out of sample testing in order to make our findings comparable to those in the literature, and to hew to the tradition of the original Meese-Rogoff papers. 
where $X_{t}$ is a vector of fundamental variables under consideration. The first-difference specification involves the following regression:

$$
\Delta_{S_{t}}=\Delta X_{t} \Gamma+u_{t} .
$$

These estimates are then used to generate one- and multi-quarter ahead forecasts. Since these exchange rate models imply joint determination of all variables in the equations, it makes sense to apply instrumental variables. However, previous experience indicates that the gains in consistency are far outweighed by the loss in efficiency, in terms of prediction (Chinn and Meese, 1995). Hence, we rely solely on OLS.

The error correction estimation involves a two step procedure. In the first step, the longrun cointegrating relation implied by (5) is identified using the Johansen procedure. The estimated cointegrating vector $(\tilde{\Gamma})$ is incorporated into the error correction term, and the resulting equation

$$
s_{t}-s_{t-k}=\delta_{0}+\delta_{1}\left(s_{t-k}-X_{t-k} \tilde{\Gamma}\right)+u_{t}
$$

is estimated via OLS. Equation (7) can be thought of as an error correction model stripped of short run dynamics. A similar approach was used in Mark (1995) and Chinn and Meese (1995), except for the fact that in those two cases, the cointegrating vector was imposed a priori.

One key difference between our implementation of the error correction specification and that undertaken in some other studies involves the treatment of the cointegrating vector. In some other prominent studies (MacDonald and Taylor, 1993), the cointegrating relationship is estimated over the entire sample, and then out of sample forecasting undertaken, where the short run dynamics are treated as time varying but the long-run relationship is not. While there are good reasons for adopting this approach - in particular one wants to use as much information as possible to obtain estimates of the cointegrating relationships - the asymmetry in estimation approach is troublesome, and makes it difficult to distinguish quasi-ex ante forecasts from true ex ante forecasts. Consequently, our estimates of the long-run cointegrating relationship vary as the data window moves.

It is also useful to stress the difference between the error correction specification forecasts and the first-difference specification forecasts. In the latter, ex post values of the right 
hand side variables are used to generate the predicted exchange rate change. In the former, contemporaneous values of the right hand side variables are not necessary, and the error correction predictions are true ex ante forecasts. Hence, we are affording the first-difference specifications a tremendous informational advantage in forecasting. ${ }^{8}$

\subsection{Forecast Comparison}

To evaluate the forecasting accuracy of the different structural models, the ratio between the mean squared error (MSE) of the structural models and a driftless random walk is used. ${ }^{9} \mathrm{~A}$ value smaller (larger) than one indicates a better performance of the structural model (random walk). We also explicitly test the null hypothesis of no difference in the accuracy of the two competing forecasts (i.e. structural model vs. driftless random walk). In particular, we use the Diebold-Mariano statistic (Diebold and Mariano, 1995) which is defined as the ratio between the sample mean loss differential and an estimate of its standard error; this ratio is asymptotically distributed as a standard normal. ${ }^{10}$ The loss differential is defined as the difference between the squared forecast error of the structural models and that of the random walk. A consistent estimate of the standard deviation can be constructed from a weighted sum of the available

${ }^{8}$ We opted to exclude short-run dynamics in equation (7) because a) the use of equation (7) yields true ex ante forecasts and makes our exercise directly comparable with, for example, Mark (1995), Chinn and Meese (1995) and Groen (2000), and b) the inclusion of short-run dynamics creates additional demands on the generation of the right-hand-side variables and the stability of the short-run dynamics that complicate the forecast comparison exercise beyond a manageable level.

${ }^{9}$ The comparison could also be made against a random walk with estimated drift, as suggested by Kilian (1999). We opted not to make this comparison for two reasons. First, over the long samples we are examining, the drift term would be approximately zero (except perhaps for the yen). Second, it is typically easier to outperform a random walk with drift benchmark; hence, in selecting this reference model, we are being conservative by biasing our results against finding structural model performance.

${ }^{10}$ In using the DM test, we are relying upon asymptotic results, which may or may not be appropriate for our sample. However, generating finite sample critical values for the large number of cases we deal with would be computationally infeasible. More importantly, the most likely outcome of such an exercise would be to make detection of statistically significant outperformance even more rare, and leaving our basic conclusion intact. 
sample autocovariances of the loss differential vector. Following Andrews (1991), a quadratic spectral kernel is employed, together with a data-dependent bandwidth selection procedure. ${ }^{11}$

We also examine the predictive power of the various models along different dimensions. One might be tempted to conclude that we are merely changing the well-established "rules of the game" by doing so. However, there are very good reasons to use other evaluation criteria. First, there is the intuitively appealing rationale that minimizing the mean squared error (or relatedly mean absolute error) may not be important from an economic standpoint. A less pedestrian motivation is that the typical mean squared error criterion may miss out on important aspects of predictions, especially at long horizons. Christoffersen and Diebold (1998) point out that the standard mean squared error criterion indicates no improvement of predictions that take into account cointegrating relationships vis à vis univariate predictions. But surely, any reasonable criteria would put some weight the tendency for predictions from cointegrated systems to "hang together".

Hence, our first alternative evaluation metric for the relative forecast performance of the structural models is the direction of change statistic, which is computed as the number of correct predictions of the direction of change over the total number of predictions. A value above (below) 50 per cent indicates a better (worse) forecasting performance than a naive model that predicts the exchange rate has an equal chance to go up or down. Again, Diebold and Mariano (1995) provide a test statistic for the null of no forecasting performance of the structural model. The statistic follows a binomial distribution, and its studentized version is asymptotically distributed as a standard normal. Not only does the direction of change statistic constitute an alternative metric, it is also an approximate measure of profitability. We have in mind here tests for market timing ability (Cumby and Modest, 1987). ${ }^{12}$

The third metric we used to evaluate forecast performance is the consistency criterion

${ }^{11}$ We also experienced with the Bartlett kernel and the deterministic bandwidth selection method. The results from these methods are qualitatively very similar. Appendix 2 contains a more detailed discussion of the forecast comparison tests.

${ }^{12}$ See also Leitch and Tanner (1991), who argue that a direction of change criterion may be more relevant for profitability and economic concerns, and hence a more appropriate metric than others based on purely statistical motivations. 
proposed in Cheung and Chinn (1998). This metric focuses on the time-series properties of the forecast. The forecast of a given spot exchange rate is labeled as consistent if (1) the two series have the same order of integration, (2) they are cointegrated, and (3) the cointegration vector satisfies the unitary elasticity of expectations condition. Loosely speaking, a forecast is consistent if it moves in tandem with the spot exchange rate in the long run. Cheung and Chinn (1998) provide a more detailed discussion on the consistency criterion and its implementation.

\section{Comparing the Forecast Performance}

\subsection{The MSE Criterion}

The comparison of forecasting performance based on MSE ratios is summarized in Table 1. The Table contains MSE ratios and the p-values from five dollar-based currency pairs, four structural models, the error correction and first-difference specifications, three forecasting horizons, and two forecasting samples. Each cell in the Table has two entries. The first one is the MSE ratio (the MSEs of a structural model to the random walk specification). The entry underneath the MSE ratio is the p-value of the hypothesis that the MSEs of the structural and random walk models are the same. Because of the lack of data, the behavioral equilibrium exchange rate model is not estimated for the dollar-Swiss franc and dollar-yen exchange rates. Altogether, there are $186 \mathrm{MSE}$ ratios, which spread evenly across the two forecasting samples. Of these 186 ratios, 108 are computed from the error correction specification and 78 from the first-difference one.

Note that in the tables, only "error correction specification" entries are reported for the interest rate parity model. In fact, this model is not estimated; rather the predicted spot rate is calculated using the uncovered interest parity condition. To the extent that long term interest rates can be considered the error correction term, we believe this categorization is most appropriate.

Overall, the MSE results are not favorable to the structural models. Of the $186 \mathrm{MSE}$ ratios, 141 are not significant (at the 10\% significance level) and 45 are significant. That is, for the majority cases one cannot differentiate the forecasting performance between a structural model and a random walk model. For the 45 significant cases, there are 43 cases in which the 
random walk model is significantly better than the competing structural models and only 2 cases in which the opposite is true. The significant cases are quite evenly distributed across the two forecasting periods. As $10 \%$ is the size of the test and 3 cases constitute less than $10 \%$ of the total of 186 cases, the empirical evidence can hardly be interpreted as supportive of the superior forecasting performance of the structural models.

Inspection of the MSE ratios, does not reveal many consistent patterns in terms of outperformance. It appears that the productivity model does not do particularly badly for the dollar-mark rate at the 1- and 4-quarter horizons. The MSE ratios of the interest rate parity model are less than unity only at the 20 -quarter horizon - a finding consistent with the wellknown bias in forward rates at short horizons.

The MSE results derived from the yen-based exchange rates are provided in Table 2, which has a format similar to that of Table 1. As we lack data to estimate the behavioral equilibrium exchange rate model for yen-based exchange rates, Table 2 contains only $150 \mathrm{MSE}$ ratios and the p-values of the hypothesis that the MSEs of the structural and random walk models are the same. Again, the structural models do not deliver a better forecasting performance than a random walk model. Indeed, compared with the dollar-based exchange rates, the yen-based exchange rates have a larger fraction of cases in which one cannot differentiate the forecasting performance between a structural model and a random walk model. In 126 out of 150 cases, the statistic is not significant. Of the significant cases, the random walk model outperforms in 20 cases and the competing structural models do better in 4 cases. Again, the frequency of observing a structural model forecast better than a random walk model is lower than that implied by the size of the test.

Consistent with the existing literature, our results are supportive of the assertion that it is very difficult to find forecasts from a structural model that can consistently beat the random walk model using the MSE criterion. The current exercise further strengthens the assertion as it covers both dollar- and yen-based exchange rates, two different forecasting periods, and some structural models that have not been extensively studied before. 


\subsection{The Direction of Change Criterion}

Table 3 reports the proportion of forecasts that correctly predict the direction of the dollar exchange rate movement and, underneath these sample proportions, the p-values for the hypothesis that the reported proportion is significantly different from $1 / 2$. When the proportion statistic is significantly larger than $1 / 2$, the forecast is said to have the ability to predict the direct of change. On the other hand, if the statistic is significantly less than $1 / 2$, the forecast tends to give the wrong direction of change. For trading purposes, information regarding the significance of incorrect prediction can be used to derive a potentially profitable trading rule by going again the prediction generated by the model. Following this argument, one might consider the cases in which the proportion of "correct" forecasts is larger than or less than $1 / 2$ contain the same information. However, in evaluating the ability of the model to describe exchange rate behavior, we separate the two cases.

There is mixed evidence on the ability of the structural models to correctly predict the direction of change. Among the 186 direction of change statistics, 32 (22) are significantly larger (less) than $1 / 2$ at the $10 \%$ level. The occurrence of the significant outperformance cases is higher $(17 \%)$ than the one implied by the $10 \%$ level of the test. The results indicate that the structural model forecasts can correctly predict the direction of the change, while the proportion of cases where a random walk outperforms the competing models is only about what one would expect if they occurred randomly.

Let us take a closer look at the incidences in which the forecasts are in the right direction. Approximately $1 / 3$ of the 32 cases are associated with the error correction model and the remainder with the first difference specification. Thus, it is not clear if the error correction specification - which incorporates the empirical long-run relationship - is a better specification for the models under consideration. The forecasting period does not have a major impact on forecasting performance, since exactly half of the successful cases are in each forecasting period.

Among the four models under consideration, the sticky-price model has the highest number (10) of forecasts that give the correct direction of change prediction, closely followed by the behavioral equilibrium exchange rate and productivity models ( 9 and 8 respectively), and the 
interest rate parity model (5). Thus, at least on this count, the newer exchange rate models do not edge out the "old fashioned" sticky-price model. Because there are differing numbers of forecasts due to data limitations and specifications, the proportions do not exactly match up with the numbers. Proportionately, the behavioral equilibrium exchange rate model does the best.

Interestingly, the success of direction of change prediction appears to be currency specific. The dollar-yen exchange rate yields 9 out of 30 forecasts that give the correct direction of change prediction. In contrast, the dollar-pound has only 2 out of 42 forecasts that produce the correct direction of change prediction.

The cases of correct direction prediction appear to cluster at the long forecast horizon. The 20-quarter horizon accounts for 14 of the 32 cases while the 4-quarter and 1-quarter horizons have 10 and 8 direction of change statistics that are significantly larger than $1 / 2$. Since there have not been many studies utilizing the direction of change statistic in similar contexts, it is difficult to make comparisons. Chinn and Meese (1995) apply the direction of change statistic to 3 year horizons for three conventional models, and find that performance is largely currencyspecific: the no change prediction is outperformed in the case of the dollar-yen exchange rate, while all models are outperformed in the case of the dollar-pound rate. In contrast, in our study at the 20-quarter horizon, the positive results appear to be fairly evenly distributed across the currencies, with the exception of the dollar-pound rate. ${ }^{13}$ Mirroring the MSE results, it is interesting to note that the direction of change statistic works for the interest rate parity model only at the 20-quarter horizon. This pattern is entirely consistent with the finding that uncovered interest parity holds better at long horizons. ${ }^{14}$

The direction of change results derived from the yen-based exchange rates are summarized in Table 4. Of the 150 yen-based direction of change statistics, 37 (or 25\%) are significantly larger than $1 / 2$ while 7 are significantly smaller. The 37 cases in which the forecasts

${ }^{13}$ Using Markov switching models, Engel (1994) obtains some success along the direction of change dimension at horizons of up to one year. However, his results are not statistically significant.

${ }^{14}$ Mark and Moh (2001) document the gradual currency appreciation in response to a short term interest differential, contrary to the predictions of uncovered interest parity. 
give correct direction of change predictions distribute evenly across the three models (sticky price, interest rate parity, and productivity differential) under consideration, although on a proportional basis the interest rate parity model garners the highest success ratio (37\%). Similar to the dollar based data, the direction of change results appear to be currency specific and the outperformance is concentrated in the pound-yen exchange rate. Among the 37 cases in which the structure models correctly predict the direction of change, the 20-quarter ahead forecast horizon accounts for 20 cases while the 1-quarter and 4-quarter ahead forecast horizons have 5 and 12 cases respectively. The direction of change outperformance is more pronounced at the long horizon. This is in line with the results of Mark (1995) and Chinn and Meese (1995).

\subsection{The Consistency Criterion}

The consistency criterion only requires the forecast and actual realization comove one-toone in the long run. One may argue that the criterion is less demanding than the MSE and direct of change metrics. Indeed, a forecast that satisfies the consistency criterion can (1) have a MSE larger than that of the random walk model, (2) have a direction of change statistic less than $1 / 2$, or (3) generate forecast errors that are serially correlated. However, given the problems related to modeling, estimation, and data quality, the consistency criterion can be a more flexible way to evaluate a forecast. In assessing the consistency, we first test if the forecast and the realization are cointegrated. ${ }^{15}$ If they are cointegrated, then we test if the cointegrating vector satisfies the $(1,-1)$ requirement. The cointegration results are reported in Tables 5 and 6 . The test results for the $(1,-1)$ restriction are reported in Tables 7 and 8.

For the dollar-based exchange rate data, 62 of 186 cases reject the null hypothesis of no cointegration at the $10 \%$ significance level. Thus, 62 forecast series (33\% of the total number) are cointegrated with the corresponding spot exchange rates. The error correction specification accounts for 34 of the 62 cointegrated cases and the first-difference specification accounts for the

15 The Johansen method is used to test the null hypothesis of no cointegration. The maximum eigenvalue statistics are reported in the manuscript. Results based on the trace statistics are essentially the same. Before implementing the cointegration test, both the forecast and exchange rate series were checked for the I(1) property. For brevity, the I(1) test results and the trace statistics are not reported. 
remaining 28 cases. There is little evidence that the error correction specification gives better forecasting performance than the first-difference specification. These 62 cointegrated cases are slightly more concentrated in the longer of the two forecasting periods -27 for the post-Louvre Accord period and 35 for the post-1983 period.

Interestingly, the sticky-price model garners the largest number of cointegrated cases. There are 60 forecast series generated under the sticky-price model. 26 of these 60 series (that is, $43 \%$ ) are cointegrated with the corresponding spot rates. The behavioral equilibrium exchange rate model has the second highest frequency of cointegrated forecast series $-39 \%$ of 36 series. $37 \%$ of the productivity differential model forecast series and $0 \%$ of the interest rate parity model are cointegrated with the spot rates. Again, we do not find evidence that the recently developed exchange rate models outperform the "old" vintage sticky-price model.

The dollar-pound and dollar-Canadian dollar, each have between 16 and 17 forecast series that are cointegrated with their respective spot rates. The dollar-mark pair, which yields relatively good forecasts according to the direction of change metric, has only 11 cointegrated forecast series. Evidently, the forecasting performance is not just currency specific; it also depends on the evaluation criterion. The distribution of the cointegrated cases across forecasting horizons is puzzling. The frequency of occurrence is inversely proportional to the forecasting horizons. There are 35 of 62 one-quarter ahead forecast series that are cointegrated with the spot rates. However, there are only 18 of the four-quarter ahead and 9 of the 20 -quarter ahead forecast series that are cointegrated with the spot rates. One possible explanation for this result is that there are fewer observations in the 20 -quarter ahead forecast series and this affects the power of the cointegration test.

The yen-based cointegration test results are presented in Table 6. The yen-based exchange rates yield a substantially larger proportion of significant cases. Of the 150 forecast series, 65 (or 43\%) series move together with the spot exchange rates in the long run. The yenbased data display slightly better forecasting performance of the error correction vs. firstdifference specifications - the former specification has 35 cointegrated forecast series and the latter has 30 .

The productivity and sticky-price models produce the largest number of cointegrated 
forecast series (28 and 27 respectively). Interestingly, along this cointegration dimension, productivity-based models fare better than along the MSE or DoC dimensions.

Among the five yen-based exchange rates, the occurrence of cointegrated forecast series ranges from the low of 8 series in the yen-dollar case to the high of 18 series in the yen-mark case. Regarding the forecasting horizon, the yen-based results are quite similar to the dollarbased ones. The cointegrated forecast series are mostly found in the one-quarter ahead forecasting horizon. In fact, it accounts for 38 of the 65 cases. The 20 -quarter ahead forecast horizon only has 7 cointegrated forecast series.

The results of testing for the long-run unitary elasticity of expectations at the $10 \%$ significance level are reported in Table 7 (dollar-based exchange rates) and Table 8 (yen-based exchange rates). The condition of long-run unitary elasticity of expectations; that is the $(1,-1)$ restriction on the cointegrating vector, is rejected by the data quite frequently. For the dollarbased exchange rates, the $(1,-1)$ restriction is rejected in 43 of the 62 cointegration cases. That is $31 \%$ of the cointegrated cases display long-run unitary elasticity of expectations. Taking both the cointegration and restriction test results together, $10 \%$ of the 186 cases of the dollar-based exchange rate forecast series meet the consistency criterion. The yen-based exchange rates yield similar results. The $(1,-1)$ restriction is rejected in 45 of the 65 cointegration cases. This leads to the conclusion that $13 \%$ of the yen-based exchange rate forecast series meet the consistency criterion.

\subsection{Discussion}

Several aspects of the foregoing analysis merit discussion. To begin with, even at long horizons, the performance of the structural models is less than impressive along the MSE dimension. This result is consistent with those in other recent studies, although we have documented this finding for a wider set of models and specifications. Groen (2000) restricted his attention to a flexible price monetary model, while Faust et al. (2001) examined a portfolio balance model as well; both remained within the MSE evaluation framework.

Setting aside issues of statistical significance, it is interesting that long horizon error correction specifications are over-represented in the set of cases where a random walk is 
outperformed. Indeed, the interest rate parity model at the 20 -quarter horizon accounts for many of the MSE ratio entries that are less than unity ( 7 of 17 error correction dollar based entries, and 11 of 30 yen based entries).

Expanding the set of criteria does yield some interesting surprises. In particular, the direction of change statistics indicate more evidence that structural models can outperform a random walk. However, the basic conclusion that no specific economic model is consistently more successful than the others remains intact. This, we believe, is a new finding.

Even if we cannot glean from this analysis a consistent "winner", it may still be of interest to note the best and worst performing combinations of model/specification/currency. The best performance on the MSE criterion is turned in by the interest rate parity model at the 20quarter horizon for the Canadian dollar-yen exchange rate (post-1982), with a MSE ratio of 0.48 (p-value of 0.04). Figure 3 plots the actual Canadian dollar-yen exchange rate, 20-quarters interest rate parity and random walk forecasts. The graph shows that forecast performance of the interest parity model varies across time. Forecasts from the interest rate parity condition track the actual exchange rate movements pretty well during 1985-1990 and 1993-1997. The random walk, however, forecasts better in the other periods.

Note, however, that the superior performance of a particular model/specification/currency combination does not necessarily carry over from one out-ofsample period to the other. That is the lowest dollar-based MSE ratio during the 1987q2-2000q4 period is for the Deutsche mark behavioral equilibrium exchange rate model in first differences, while the corresponding entry for the 1983q1-2000q4 period is the for the yen interest parity model.

The worst performances are associated with first-difference specifications; in this case the highest MSE ratio is for the first differences specification of the behavioral equilibrium exchange rate model at the 20 -quarter horizon for the pound- dollar exchange rateover the postLouvre period However, the other catastrophic failures in prediction performance are distributed across the various models estimated in first differences, so (taking into account the fact that these predictions utilize ex post realizations of the right hand side variables) the key determinant in this pattern of results appears to be the difficulty in estimating stable short run dynamics. 
That being said, we do not wish to overplay the stability of the long run estimates we obtain. Even in cases where the structural model does reasonably well, there is quite substantial time-variation in the estimate of the rate at which the exchange rate responds to disequilibria. A similar observation applies to the coefficient estimates of the parameters of the cointegrating vector.

One question that might occur to the reader is whether our results are sensitive to the outof-sample period we have selected. In fact, it is possible to improve the performance of the models according to a MSE criterion by selecting a shorter out-of-sample forecasting period. In another set of results (not reported), we implemented the same exercises for a 1993q1-2000q4 period, and found somewhat greater success for dollar based rates according to the MSE criterion, and somewhat less success along the direction of change dimension. We believe that the difference in results is an artifact of the long upswing in the dollar during the 1990's, that gives an advantage to structural models over the no-change forecast embodied in the random walk model when using the most recent eight years of the floating rate period as the prediction sample. This conjecture is buttressed by the fact that the yen-based exchange rates did not exhibit a similar pattern of results. Thus, in using fairly long out-of-sample periods, as we have done, we have given maximum advantage to the random walk characterization.

\section{Concluding Remarks}

This paper has systematically assessed the predictive capabilities of models developed during the 1990's. These models have been compared along a number of dimensions, including econometric specification, currencies, out-of-sample prediction periods, and differing metrics.

At this juncture, it may be useful to outline the boundaries of this study. Firstly, we have only evaluated linear models, eschewing functional nonlinearities (Meese and Rose, 1991; Kilian and Taylor, 2001) and regime switching (Engel and Hamilton, 1990). Nor have we employed panel regression techniques in conjunction with long run relationships, despite the fact that recent evidence suggests the potential usefulness of such approaches (Mark and Sul, 2001). Finally, we did not undertake systems-based estimation that has been found in certain circumstances to yield superior forecast performance, even at short horizons (e.g., MacDonald 
and Marsh, 1997). Such a methodology would have proven much too cumbersome to implement in the cross-currency recursive framework employed in this study. Consequently, one could view this exercise as a first pass examination of these newer exchange rate models.

In summarizing the evidence from this exhaustive analysis, we conclude that the answer to the question posed in the title of this paper is a bold "perhaps." That is, the results do not point to any given model/specification combination as being very successful. On the other hand, some models seem to do well at certain horizons, for certain criteria. And indeed, it may be that one model will do well for one exchange rate, and not for another. For instance, the productivity model does well for the mark-yen rate along the direction of change and consistency dimensions (although not by the MSE criterion); but that same conclusion cannot be applied to any other exchange rate. Perhaps it is in this sense that the results from this study set the stage for future research. 


\section{References}

Alberola, Enrique, Susana Cervero, Humberto Lopez and Angel Ubide, 1999, “Global Equilibrium Exchange Rates: Euro, Dollar, 'Ins', 'Outs', and Other Major Currencies in a Panel Cointegration Framework," IMF Working Paper 99/175.

Alexius, Annika, 2001, “Uncovered Interest Parity Revisited," Review of International Economics 9(3): 505-517.

Andrews Donald, 1991, "Heteroskedasticity and Autocorrelation Consistent Covariance Matrix Estimation," Econometrica 59: 817-858.

Cavallo, Michele and Fabio Ghironi, 2002, "Net Foreign Assets and the Exchange Rate: Redux Revived," mimeo (NYU and Boston College, February).

Cheung, Yin-Wong and Menzie Chinn, 1998, "Integration, Cointegration, and the Forecast Consistency of Structural Exchange Rate Models," Journal of International Money and Finance 17(5): 813-830.

Chinn, Menzie, 1997, "Paper Pushers or Paper Money? Empirical Assessment of Fiscal and Monetary Models of Exchange Rate Determination," Journal of Policy Modeling 19(1): 51-78.

Chinn, Menzie and Richard Meese, 1995, "Banking on Currency Forecasts: How Predictable Is Change in Money?" Journal of International Economics 38(1-2): 161-178.

Christoffersen, Peter F. and Francis X. Diebold, 1998, "Cointegration and Long-Horizon Forecasting," Journal of Business and Economic Statistics 16: 450-58.

Clark, Peter and Ronald MacDonald, 1999, "Exchange Rates and Economic Fundamentals: A Methodological Comparison of Beers and Feers," in J. Stein and R. MacDonald (eds.) Equilibrium Exchange Rates (Kluwer: Boston), pp. 285-322.

Clements, Kenneth, and Jacob Frenkel, 1980, "Exchange Rates, Money and Relative Prices: The Dollar-Pound in the 1920s," Journal of International Economics 10: 249-262.

Clostermann, Jörg, and Bernd Schnatz, 2000, "The Determinants of the Euro-Dollar Exchange Rate: Synthetic Fundamentals and a Non-Existent Currency," Discussion Paper 2/00 (Frankfurt: Deutsche Bundesbank, May).

Cumby, Robert E. and David M. Modest, 1987, “Testing for Market Timing Ability: A

Framework for Forecast Evaluation," Journal of Financial Economics 19(1): 169-89.

DeGregorio, Jose and Holger Wolf, 1994, "Terms of Trade, Productivity, and the Real Exchange 
Rate," NBER Working Paper \#4807 (July).

Dornbusch, Rudiger. 1976. "Expectations and Exchange Rate Dynamics," Journal of Political Economy 84: 1161-76.

Diebold F., Mariano R., 1995, “Comparing Predictive Accuracy," Journal of Business and Economic Statistics 13: 253-265.

Economist, 2001, "Finance and Economics: The darling dollar," Economist, Apr 7, 2001, pp. 8182.

Engel, Charles, 1994, “Can the Markov Switching Model Forecast Exchange Rates?" Journal of International Economics 36(1-2):151-165.

Engel, Charles and James Hamilton, 1990, "Long Swings in the Exchange Rate: Are They in the Data and Do Markets Know It?" American Economic Review 80 (4): 689-713.

Faruqee, Hamid, Peter Isard and Paul R. Masson, 1999, “A Macroeconomic Balance Framework for Estimating Equilibrium Exchange Rates," in J. Stein and R. MacDonald (eds.) Equilibrium Exchange Rates (Kluwer: Boston), pp. 103-134.

Faust, Jon, John Rogers and Jonathan Wright, 2001, "Exchange Rate Forecasting: The Errors We've Really Made," paper presented at conference on "Empirical Exchange Rate Models," U.Wisconsin, September 28-29. Forthcoming, Journal of International Economics.

Fels, Joachim and Fatih Yilmaz, 2001, "Where Is the Fair Value of the Euro?" Morgan Stanley Dean Witter (January 18).

Frankel, Jeffrey A., 1979, "On the Mark: A Theory of Floating Exchange Rates Based on Real Interest Differentials," American Economic Review 69: 610-622.

Frankel, Jeffrey, 1985, “The Dazzling Dollar,” Brookings Papers on Economic Activity 1985(1), 199-217.

Groen, Jan J.J., 2000, “The Monetary Exchange Rate Model as a Long-Run Phenomenon,” Journal of International Economics 52(2): 299-320.

Kilian, Lutz, 1999, "Exchange Rates and Monetary Fundamentals: What Do We Learn from Long-Horizon Regressions?" Journal of Applied Econometrics 14: 491-510.

Kilian, Lutz and Mark Taylor, 2001, "Why Is It So Difficult to Beat the Random Walk Forecast of Exchange Rates," paper presented at conference on "Empirical Exchange Rate Models," U.Wisconsin, September 28-29. Forthcoming, Journal of International 


\section{Economics.}

Lane, Philip and Milesi-Ferretti Gian Maria, 2001, "The External Wealth of Nations: Measures of Foreign Assets and Liabilities for Industrial and Developing," Journal of International Economics 55: 263-294.

Leitch, Gordon and J. Ernest Tanner, 1991, "Economic Forecast Evaluation: Profits Versus the Conventional Error Measures," American Economic Review 81(3): 580-90.

Lucas, Robert, 1982, "Interest Rates and Currency Prices in a Two-Country World," Journal of Monetary Economics 10(3): 335-359.

MacDonald, Ronald and Ian Marsh, 1997, "On Fundamentals and Exchange Rates: A Casselian Perspective," Review of Economics and Statistics 79(4) (November): 655-664.

MacDonald, Ronald and Ian Marsh, 1999, Exchange Rate Modeling (Boston: Kluwer).

MacDonald, Ronald and Jun Nagayasu, 2000, “The Long-Run Relationship between Real Exchange Rates and Real Interest Rate Differentials," IMF Staff Papers 47(1).

MacDonald, Ronald and Taylor, Mark P., 1994, "The Monetary Model of the Exchange Rate: Long-run Relationships, Short-run Dynamics and How to Beat a Random Walk," Journal of International Money \& Finance 13(3): 276-290.

Maeso-Fernandez, Francisco, Chiara Osbat and Bernd Schnatz, 2001, "Determinants of the Euro Real Effective Exchange Rate: A BEER/PEER Approach,” ECB Working Paper No. 85 (Frankfurt: ECB, November).

Mark, Nelson, 1995, "Exchange Rates and Fundamentals: Evidence on Long Horizon Predictability," American Economic Review 85: 201-218.

Mark, Nelson and Young-Kyu Moh, 2001, “What Do Interest-Rate Differentials Tell Us about the Exchange Rate," paper presented at conference on "Empirical Exchange Rate Models," U.Wisconsin, September 28-29. Forthcoming, Journal of International Economics.

Mark, Nelson and Donggyu Sul, 2001, "Nominal Exchange Rates and Monetary Fundamentals: Evidence from a Small post-Bretton Woods Panel," Journal of International Economics 53(1) (February): 29-52.

Meese, Richard, and Kenneth Rogoff, 1983, "Empirical Exchange Rate Models of the Seventies: Do They Fit Out of Sample?” Journal of International Economics 14: 3-24.

Meese, Richard, and Kenneth Rogoff, 1988, "Was It Real? The Exchange Rate-Interest 
Differential Relation over the Modern Floating-Rate Period," Journal of Finance 43 (4) (September): 933-47.

Meese, Richard, and Andrew K. Rose, 1991, "An Empirical Assessment of Non-Linearities in Models of Exchange Rate Determination,” Review of Economic Studies 58 (3): 603-619.

Meredith, Guy and Menzie Chinn, 1998, "Long-Horizon Uncovered Interest Rate Parity,” NBER Working Paper \#6797 (November).

Obstfeld, Maurice and Kenneth Rogoff, 1995, “Exchange Rate Dynamics Redux, ”Journal of Political Economy 91: 675-687.

Rosenberg, Michael, 2001, "Investment Strategies based on Long-Dated Forward Rate/PPP Divergence," FX Weekly (New York: Deutsche Bank Global Markets Research, 27 April), pp. 4-8.

Stein, Jerome, 1999, "The Evolution of the Real Value of the US Dollar Relative to the G7 Currencies," in J. Stein and R. MacDonald (eds.) Equilibrium Exchange Rates (Kluwer: Boston), pp. 67-102.

Stockman, Alan, 1980, "A Theory of Exchange Rate Determination," Journal of Political Economy 88(4): 673-698.

Yilmaz, Fatih and Stephen Jen, 2001, "Correcting the US Dollar - A Technical Note," Morgan Stanley Dean Witter (June 1). 


\section{Appendix 1: Data}

Unless otherwise stated, we use seasonally-adjusted quarterly data from the IMF International Financial Statistics ranging from the second quarter of 1973 to the last quarter of 2000 . The exchange rate data are end of period exchange rates. The output data are measured in constant 1990 prices. The consumer and producer price indexes also use 1990 as base year. Inflation rates are calculated as 4-quarter log differences of the CPI. Real interest rates are calculated by subtracting the lagged inflation rate from the 3 month nominal interest rates.

The three-month, annual and five-year interest rates are end-of-period constant maturity interest rates, and are obtained from the IMF country desks. See Meredith and Chinn (1998) for details. Five year interest rate data were unavailable for Japan and Switzerland; hence data from Global Financial Data http://www.globalfindata.com/ were used, specifically, 5-year government note yields for Switzerland and 5-year discounted bonds for Japan.

The productivity series are labor productivity indices, measured as real GDP per employee, converted to indices $(1995=100)$. These data are drawn from the Bank for International Settlements database.

The net foreign asset (NFA) series is computed as follows. Using stock data for year 1995 on NFA (Lane and Milesi-Ferretti, 2001) at http://econserv2.bess.tcd.ie/plane/data.html, and flow quarterly data from the IFS statistics on the current account, we generated quarterly stocks for the NFA series (with the exception of Japan, for which there is no quarterly data available on the current account).

To generate quarterly government debt data we follow a similar strategy. We use annual debt data from the IFS statistics, combined with quarterly government deficit (surplus) data. The data source for Canadian government debt is the Bank of Canada. For the UK, the IFS data are updated with government debt data from the public sector accounts of the UK Statistical Office 
(for Japan and Switzerland we have very incomplete data sets, and hence no behavioral equilibrium exchange rate models are estimated for these two countries). 


\section{Appendix 2: Evaluating Forecast Accuracy}

The Diebold-Mariano statistics (Diebold and Mariano, 1995) are used to evaluate the forecast performance of the different model specifications relative to that of the naive random walk.

Given the exchange rate series $x_{t}$ and the forecast series $y_{t}$, the loss function $L$ for the mean square error is defined as:

$$
L\left(y_{t}\right)=\left(y_{t}-x_{t}\right)^{2} .
$$

Testing whether the performance of the forecast series is different from that of the naive random walk forecast $z_{t}$, it is equivalent to testing whether the population mean of the loss differential series $d_{t}$ is zero. The loss differential is defined as

$$
d_{t}=L\left(y_{t}\right)-L\left(z_{t}\right) .
$$

Under the assumptions of covariance stationarity and short-memory for $d_{t}$, the large-sample statistic for the null of equal forecast performance is distributed as a standard normal, and can be expressed as

$$
\frac{\bar{d}}{\sqrt{2 \pi \sum_{\tau=-(T-1)}^{(T-1)} l(\tau / S(T)) \sum_{t=|\tau|+1}^{T}\left(d_{t}-\bar{d}\right)\left(d_{t-|\tau|}-\bar{d}\right)}},
$$

where $l(\tau / S(T))$ is the lag window, $S(T)$ is the truncation lag, and $T$ is the number of observations. Different lag-window specifications can be applied, such as the Barlett or the quadratic spectral kernels, in combination with a data-dependent lag-selection procedure (Andrews, 1991).

For the direction of change statistic, the loss differential series is defined as follows: $d_{t}$ takes a value of one if the forecast series correctly predicts the direction of change, otherwise it will take a value of zero. Hence, a value of $\bar{d}$ significantly larger than 0.5 indicates that the forecast has the ability to predict the direction of change; on the other hand, if the statistic is significantly less than 0.5 , the forecast tends to give the wrong direction of change. In large samples, the 
studentized version of the test statistic,

(A4) $\frac{\bar{d}-0.5}{\sqrt{0.25 / T}}$,

is distributed as a standard Normal. 
Table 1: The MSE Ratios from the Dollar-Based Exchange Rates

\begin{tabular}{|c|c|c|c|c|c|c|c|c|c|}
\hline \multirow[b]{2}{*}{ Specification } & \multirow[b]{2}{*}{ Horizon } & \multicolumn{4}{|c|}{ Sample 1: 1987 Q2 - 2000 Q4 } & \multicolumn{4}{|c|}{ Sample 2: 1983 Q1-2000 Q4 } \\
\hline & & S-P & IRP & PROD & BEER & S-P & IRP & PROD & BEER \\
\hline \multicolumn{10}{|c|}{ Panel A: BP/\$ } \\
\hline \multirow[t]{6}{*}{ ECM } & 1 & 1.0465 & 1.0081 & 0.9954 & 1.0853 & 1.0499 & 1.0455 & 1.0418 & 1.0487 \\
\hline & & 0.4089 & 0.8832 & 0.8968 & 0.2083 & 0.3098 & 0.3183 & 0.3030 & 0.4484 \\
\hline & 4 & 1.1273 & 1.0918 & 1.0169 & 1.0993 & 1.1416 & 1.1228 & 1.0850 & 1.1272 \\
\hline & & 0.5031 & 0.6204 & 0.8022 & 0.2532 & 0.1714 & 0.3095 & 0.2369 & 0.2245 \\
\hline & 20 & 1.8089 & 1.3421 & 1.0953 & 1.3395 & 1.4568 & 0.8406 & 1.5450 & 2.1793 \\
\hline & & 0.0143 & 0.2402 & 0.4109 & 0.1684 & 0.0707 & 0.5178 & 0.0918 & 0.0570 \\
\hline \multirow[t]{6}{*}{ FD } & 1 & 1.0411 & & 1.0055 & 1.1914 & 1.0858 & & 1.0792 & 1.0230 \\
\hline & & 0.4337 & & 0.9399 & 0.2167 & 0.1345 & & 0.3367 & 0.9010 \\
\hline & 4 & 1.1195 & & 1.1235 & 1.8806 & 1.2498 & & 1.4551 & 1.4476 \\
\hline & & 0.3147 & & 0.5237 & 0.0008 & 0.1487 & & 0.1755 & 0.3510 \\
\hline & 20 & 1.8908 & & 2.5310 & 6.9525 & 3.2231 & & 5.5574 & 6.0151 \\
\hline & & 0.1769 & & 0.0205 & 0.0000 & 0.1953 & & 0.0189 & 0.0013 \\
\hline \multicolumn{10}{|c|}{ Panel B: CAN\$/\$ } \\
\hline \multirow[t]{6}{*}{ ECM } & 1 & 1.0540 & 1.0903 & 1.1480 & 1.2783 & 1.0560 & 1.0920 & 1.0409 & 1.3371 \\
\hline & & 0.1265 & 0.0477 & 0.0622 & 0.0157 & 0.2789 & 0.0216 & 0.5523 & 0.0037 \\
\hline & 4 & 1.1018 & 1.1722 & 1.1815 & 1.6025 & 1.1161 & 1.1696 & 1.0165 & 1.7540 \\
\hline & & 0.1808 & 0.4516 & 0.1571 & 0.1183 & 0.3342 & 0.3589 & 0.9290 & 0.0175 \\
\hline & 20 & 0.9394 & 0.8649 & 1.0903 & 1.7595 & 1.0615 & 0.8128 & 1.0970 & 1.6233 \\
\hline & & 0.5741 & 0.7602 & 0.3084 & 0.0018 & 0.7268 & 0.6072 & 0.3184 & 0.0001 \\
\hline \multirow[t]{6}{*}{ FD } & 1 & 1.0998 & & 1.1145 & 0.6144 & 1.1009 & & 1.1708 & 0.6662 \\
\hline & & 0.1789 & & 0.1381 & 0.1094 & 0.2573 & & 0.0469 & 0.1513 \\
\hline & 4 & 1.1367 & & 1.1604 & 0.8993 & 1.1957 & & 1.2688 & 1.1431 \\
\hline & & 0.4605 & & 0.3413 & 0.7980 & 0.3470 & & 0.1923 & 0.7041 \\
\hline & 20 & 0.5152 & & 0.5041 & 1.9236 & 1.8924 & & 2.0043 & 2.2886 \\
\hline & & 0.1931 & & 0.1816 & 0.0058 & 0.1824 & & 0.1427 & 0.2043 \\
\hline \multicolumn{10}{|c|}{ Panel C: DM/\$ } \\
\hline \multirow[t]{6}{*}{ ECM } & 1 & 1.0589 & 1.0302 & 1.0413 & 0.9951 & 1.1047 & 1.0285 & 0.9965 & 0.9109 \\
\hline & & 0.4642 & 0.2949 & 0.5737 & 0.9554 & 0.4157 & 0.3636 & 0.9614 & 0.2059 \\
\hline & 4 & 1.0804 & 1.1363 & 1.0799 & 1.1156 & 1.1040 & 1.0627 & 0.9487 & 0.8976 \\
\hline & & 0.4444 & 0.0690 & 0.2820 & 0.6423 & 0.5986 & 0.4853 & 0.6255 & 0.5576 \\
\hline & 20 & 1.0467 & 0.5960 & 1.1311 & 2.1370 & 1.7712 & 0.8953 & 1.2596 & 0.6330 \\
\hline & & 0.6367 & 0.1672 & 0.1411 & 0.2159 & 0.2121 & 0.6561 & 0.0393 & 0.2018 \\
\hline \multirow[t]{6}{*}{ FD } & 1 & 1.2675 & & 1.3235 & 0.5553 & 1.1225 & & 1.1963 & 0.6941 \\
\hline & & 0.0516 & & 0.1059 & 0.0013 & 0.0169 & & 0.0844 & 0.0203 \\
\hline & 4 & 1.4024 & & 1.6067 & 0.8438 & 1.0765 & & 1.2808 & 1.1513 \\
\hline & & 0.0243 & & 0.0300 & 0.5710 & 0.4524 & & 0.0093 & 0.6117 \\
\hline & 20 & 1.8136 & & 1.9266 & 2.5215 & 1.7226 & & 1.9640 & 3.9752 \\
\hline & & 0.1750 & & 0.1139 & 0.1396 & 0.2459 & & 0.1212 & 0.0025 \\
\hline
\end{tabular}


Table 1 (Continued)

\begin{tabular}{|c|c|c|c|c|c|c|c|c|c|}
\hline \multirow[b]{2}{*}{ Specification } & \multirow[b]{2}{*}{ Horizon } & \multicolumn{4}{|c|}{ Sample 1: 1987 Q2 - 2000 Q4 } & \multicolumn{4}{|c|}{ Sample 2: 1983 Q1-2000 Q4 } \\
\hline & & S-P & IRP & PROD & BEER & S-P & IRP & PROD & BEER \\
\hline \multicolumn{10}{|c|}{ Panel D: SF/\$ } \\
\hline \multirow[t]{6}{*}{ ECM } & 1 & 1.0741 & 1.0511 & 1.0238 & . & 0.9945 & 1.0497 & 1.0516 & . \\
\hline & & 0.1868 & 0.1384 & 0.5152 & . & 0.9062 & 0.1408 & 0.5811 & . \\
\hline & 4 & 1.2689 & 1.1832 & 1.1844 & . & 1.0019 & 1.1220 & 1.1362 & . \\
\hline & & 0.0148 & 0.0589 & 0.3666 & . & 0.9816 & 0.2477 & 0.1486 & . \\
\hline & 20 & 1.6208 & 1.4894 & 0.9694 & . & 1.3665 & 1.4894 & 1.3774 & . \\
\hline & & 0.0685 & 0.0000 & 0.9335 & . & 0.0456 & 0.0000 & 0.0107 & . \\
\hline \multirow[t]{6}{*}{ FD } & 1 & 1.1057 & & 1.0904 & . & 1.0886 & & 1.0672 & . \\
\hline & & 0.1889 & & 0.3506 & . & 0.2373 & & 0.5446 & . \\
\hline & 4 & 1.3615 & & 1.4677 & . & 1.2321 & & 1.3318 & . \\
\hline & & 0.0037 & & 0.0005 & . & 0.1532 & & 0.0501 & . \\
\hline & 20 & 2.4774 & & 2.6569 & . & 1.5404 & & 1.8696 & . \\
\hline & & 0.0394 & & 0.0491 & . & 0.5211 & & 0.3938 & . \\
\hline \multicolumn{10}{|c|}{ Panel E: Yen/\$ } \\
\hline \multirow[t]{6}{*}{ ECM } & 1 & 1.0672 & 1.0494 & 1.0726 & . & 1.0079 & 1.0321 & 1.0637 & . \\
\hline & & 0.3115 & 0.2508 & 0.1249 & . & 0.9199 & 0.3607 & 0.2814 & . \\
\hline & 4 & 1.1894 & 1.1742 & 1.2391 & . & 1.0152 & 1.0482 & 1.2340 & . \\
\hline & & 0.2791 & 0.2474 & 0.1507 & . & 0.8744 & 0.6580 & 0.0035 & . \\
\hline & 20 & 0.9508 & 0.6030 & 1.0110 & . & 1.1752 & 0.5661 & 1.2349 & . \\
\hline & & 0.6470 & 0.2268 & 0.8510 & . & 0.0489 & 0.1737 & 0.0759 & . \\
\hline \multirow[t]{6}{*}{ FD } & 1 & 1.0852 & & 1.0481 & . & 1.1647 & & 1.1412 & . \\
\hline & & 0.3211 & & 0.4804 & . & 0.1790 & & 0.2196 & . \\
\hline & 4 & 1.0039 & & 1.0233 & . & 0.9937 & & 1.0116 & . \\
\hline & & 0.9776 & & 0.8814 & . & 0.9686 & & 0.9286 & . \\
\hline & 20 & 1.0808 & & 0.9725 & . & 0.9236 & & 1.0230 & . \\
\hline & & 0.9122 & & 0.9627 & . & 0.8439 & & 0.9566 & . \\
\hline
\end{tabular}

Note: The results are based on dollar-based exchange rates and their forecasts. Each cell in the Table has two entries. The first one is the MSE ratio (the MSEs of a structural model to the random walk specification). The entry underneath the MSE ratio is the p-value of the hypothesis that the MSEs of the structural and random walk models are the same (Diebold and Mariano, 1995). The notation used in the table is ECM: error correction specification; FD: first-difference specification; S-P: sticky-price model; IRP: interest rate parity model; PROD: productivity differential model; and BEER: behavioral equilibrium exchange rate model. The forecasting horizons (in quarters) are listed under the heading "Horizon." The results for the post-Louvre Accord forecasting period are given under the label "Sample 1 " and those for the post-1983 forecasting period are given under the label "Sample 2." A "." indicates the statistics are not generated due to unavailability of data. 
Table 2: The MSE Ratios from the Yen-Based Exchange Rates

\begin{tabular}{|c|c|c|c|c|c|c|c|}
\hline \multirow[b]{2}{*}{ Specification } & \multirow[b]{2}{*}{ Horizon } & \multicolumn{3}{|c|}{ Sample 1: 1987 Q2 - 2000 Q4 } & \multicolumn{3}{|c|}{ Sample 2: 1983 Q1-2000 Q4 } \\
\hline & & S-P & IRP & PROD & S-P & IRP & PROD \\
\hline \multicolumn{8}{|c|}{ Panel A: BP/Yen } \\
\hline \multirow[t]{6}{*}{ ECM } & 1 & 0.9937 & 1.0363 & 1.0873 & 1.0438 & 0.9955 & 1.0471 \\
\hline & & 0.8585 & 0.6407 & 0.3347 & 0.1254 & 0.9456 & 0.5705 \\
\hline & 4 & 1.0311 & 1.0643 & 1.1094 & 1.0990 & 0.9337 & 1.0068 \\
\hline & & 0.7357 & 0.7596 & 0.5603 & 0.1771 & 0.6834 & 0.9529 \\
\hline & 20 & 1.2997 & 0.6422 & 1.2172 & 0.7305 & 0.5262 & 0.8828 \\
\hline & & 0.0147 & 0.2453 & 0.1281 & 0.0898 & 0.1260 & 0.4380 \\
\hline \multirow[t]{6}{*}{ FD } & 1 & 1.0272 & & 1.0412 & 0.9608 & & 0.9515 \\
\hline & & 0.7921 & & 0.6781 & 0.6825 & & 0.6254 \\
\hline & 4 & 1.1758 & & 1.2496 & 0.8327 & & 0.8315 \\
\hline & & 0.4654 & & 0.3569 & 0.4272 & & 0.4115 \\
\hline & 20 & 1.8800 & & 2.1663 & 1.4420 & & 1.5873 \\
\hline & & 0.3738 & & 0.3302 & 0.5831 & & 0.4870 \\
\hline \multicolumn{8}{|c|}{ Panel B: CAN\$/Yen } \\
\hline \multirow[t]{6}{*}{ ECM } & 1 & 1.1569 & 1.0225 & 1.0830 & 1.0244 & 0.9964 & 0.9827 \\
\hline & & 0.1101 & 0.6270 & 0.0505 & 0.8506 & 0.9252 & 0.8502 \\
\hline & 4 & 1.3197 & 1.0679 & 1.0916 & 1.0386 & 0.9561 & 1.1492 \\
\hline & & 0.1194 & 0.7063 & 0.2399 & 0.8085 & 0.7305 & 0.1427 \\
\hline & 20 & 1.2658 & 0.5416 & 1.0806 & 1.2267 & 0.4774 & 1.3773 \\
\hline & & 0.0873 & 0.0562 & 0.4042 & 0.1715 & 0.0353 & 0.2400 \\
\hline \multirow[t]{6}{*}{ FD } & 1 & 1.0497 & & 1.0193 & 1.0092 & & 0.9950 \\
\hline & & 0.5369 & & 0.8017 & 0.9199 & & 0.9510 \\
\hline & 4 & 1.0918 & & 1.0984 & 0.7931 & & 0.8635 \\
\hline & & 0.6933 & & 0.7169 & 0.3591 & & 0.5372 \\
\hline & 20 & 0.8840 & & 0.8338 & 1.0639 & & 1.3366 \\
\hline & & 0.8657 & & 0.8156 & 0.9239 & & 0.6536 \\
\hline \multicolumn{8}{|c|}{ Panel C: US\$/Yen } \\
\hline \multirow[t]{6}{*}{ ECM } & 1 & 1.0672 & 1.0494 & 1.0726 & 1.0079 & 1.0321 & 1.0637 \\
\hline & & 0.3115 & 0.2508 & 0.1249 & 0.9199 & 0.3607 & 0.2814 \\
\hline & 4 & 1.1894 & 1.1742 & 1.2391 & 1.0152 & 1.0482 & 1.2340 \\
\hline & & 0.2791 & 0.2474 & 0.1507 & 0.8744 & 0.6580 & 0.0035 \\
\hline & 20 & 0.9508 & 0.6030 & 1.0110 & 1.1752 & 0.5661 & 1.2349 \\
\hline & & 0.6470 & 0.2268 & 0.8510 & 0.0489 & 0.1737 & 0.0759 \\
\hline \multirow[t]{6}{*}{ FD } & 1 & 1.0852 & & 1.0481 & 1.1647 & & 1.1412 \\
\hline & & 0.3211 & & 0.4804 & 0.1790 & & 0.2196 \\
\hline & 4 & 1.0039 & & 1.0233 & 0.9937 & & 1.0116 \\
\hline & & 0.9776 & & 0.8814 & 0.9686 & & 0.9286 \\
\hline & 20 & 1.0808 & & 0.9725 & 0.9236 & & 1.0230 \\
\hline & & 0.9122 & & 0.9627 & 0.8439 & & 0.9566 \\
\hline
\end{tabular}


Table 2: (Continued)

\begin{tabular}{|c|c|c|c|c|c|c|c|}
\hline \multirow[b]{2}{*}{ Specification } & \multirow[b]{2}{*}{ Horizon } & \multicolumn{3}{|c|}{ Sample 1: 1987 Q2 - 2000 Q4 } & \multicolumn{3}{|c|}{ Sample 2: 1983 Q1-2000 Q4 } \\
\hline & & S-P & IRP & PROD & S-P & IRP & PROD \\
\hline \multicolumn{8}{|c|}{ Panel D: DM/Yen } \\
\hline \multirow[t]{6}{*}{$\mathrm{ECM}$} & 1 & 0.9882 & 0.9858 & 1.0186 & 1.0335 & 0.9937 & 0.9836 \\
\hline & & 0.6016 & 0.7052 & 0.4558 & 0.4178 & 0.8554 & 0.6381 \\
\hline & 4 & 0.9604 & 0.9323 & 1.0319 & 0.9904 & 0.9438 & 0.9871 \\
\hline & & 0.1189 & 0.5087 & 0.6289 & 0.8168 & 0.5297 & 0.8153 \\
\hline & 20 & 1.0053 & 0.6494 & 1.0086 & 1.1873 & 0.6701 & 1.0031 \\
\hline & & 0.7024 & 0.0356 & 0.8930 & 0.3738 & 0.0179 & 0.9614 \\
\hline \multirow[t]{6}{*}{ FD } & 1 & 1.1431 & & 1.0877 & 1.1767 & & 1.0955 \\
\hline & & 0.0966 & & 0.3007 & 0.0161 & & 0.0806 \\
\hline & 4 & 1.1719 & & 1.0955 & 1.1975 & & 1.1395 \\
\hline & & 0.0656 & & 0.2848 & 0.0826 & & 0.0991 \\
\hline & 20 & 1.0127 & & 1.1023 & 1.4901 & & 1.5938 \\
\hline & & 0.9242 & & 0.5934 & 0.3031 & & 0.1752 \\
\hline \multicolumn{8}{|c|}{ Panel E: SF/Yen } \\
\hline \multirow[t]{6}{*}{ ECM } & 1 & 0.9573 & 1.0167 & 1.0940 & 1.0337 & 1.0311 & 1.1280 \\
\hline & & 0.4350 & 0.4571 & 0.1051 & 0.5142 & 0.1588 & 0.0392 \\
\hline & 4 & 0.9658 & 0.9856 & 1.2521 & 1.0675 & 1.0288 & 1.1710 \\
\hline & & 0.5579 & 0.8259 & 0.0011 & 0.2250 & 0.6722 & 0.1262 \\
\hline & 20 & 0.9443 & 0.9031 & 1.1902 & 1.1598 & 0.9031 & 1.2034 \\
\hline & & 0.2164 & 0.4856 & 0.2661 & 0.1405 & 0.4856 & 0.0194 \\
\hline \multirow[t]{6}{*}{ FD } & 1 & 1.0696 & & 1.0168 & 1.2217 & & 1.1857 \\
\hline & & 0.3140 & & 0.8153 & 0.0490 & & 0.1221 \\
\hline & 4 & 1.1656 & & 1.1169 & 1.2514 & & 1.1894 \\
\hline & & 0.0629 & & 0.1195 & 0.0791 & & 0.0572 \\
\hline & 20 & 1.7151 & & 1.6450 & 1.5828 & & 1.6124 \\
\hline & & 0.2592 & & 0.2264 & 0.1737 & & 0.1271 \\
\hline
\end{tabular}

Note: The results are based on yen-based exchange rates and their forecasts. Each cell in the Table has two entries. The first one is the MSE ratio (the MSEs of a structural model to the random walk specification). The entry underneath the MSE ratio is the p-value of the hypothesis that the MSEs of the structural and random walk models are the same (Diebold and Mariano, 1995). The notation used in the table is ECM: error correction specification; FD: first-difference specification; S-P: sticky-price model; IRP: interest rate parity model; PROD: productivity differential model; and BEER: behavioral equilibrium exchange rate model. The forecasting horizons (in quarters) are listed under the heading "Horizon." The results for the post-Louvre Accord forecasting period are given under the label "Sample 1 " and those for the post-1983 forecasting period are given under the label "Sample 2." 
Table 3: Direction of Change Statistics from the Dollar-Based Exchange Rates

\begin{tabular}{|c|c|c|c|c|c|c|c|c|c|}
\hline \multirow{2}{*}{ Specification } & \multirow[b]{2}{*}{ Horizon } & \multicolumn{4}{|c|}{ Sample 1: 1987 Q2 - 2000 Q4 } & \multicolumn{4}{|c|}{ Sample 2: 1983 Q1-2000 Q4 } \\
\hline & & S-P & IRP & PROD & BEER & S-P & IRP & PROD & BEER \\
\hline \multicolumn{10}{|l|}{ Panel A: BP/S } \\
\hline \multirow[t]{6}{*}{ ECM } & 1 & 0.5455 & 0.4643 & 0.5636 & 0.5273 & 0.5694 & 0.4110 & 0.5278 & 0.5278 \\
\hline & & 0.5002 & 0.5930 & 0.3452 & 0.6858 & 0.2386 & 0.1281 & 0.6374 & 0.6374 \\
\hline & 4 & 0.5769 & 0.5000 & 0.5192 & 0.4808 & 0.5217 & 0.4247 & 0.4638 & 0.5073 \\
\hline & & 0.2673 & 1.0000 & 0.7815 & 0.7815 & 0.7180 & 0.1979 & 0.5472 & 0.9042 \\
\hline & 20 & 0.3889 & 0.5357 & 0.4722 & 0.3611 & 0.5094 & 0.5890 & 0.4906 & 0.3585 \\
\hline & & 0.1824 & 0.5930 & 0.7389 & 0.0956 & 0.8908 & 0.1281 & 0.8908 & 0.0394 \\
\hline \multirow[t]{6}{*}{ FD } & 1 & 0.4546 & & 0.4727 & 0.4182 & 0.4722 & & 0.5000 & 0.5556 \\
\hline & & 0.5002 & & 0.6858 & 0.2249 & 0.6374 & & 1.0000 & 0.3458 \\
\hline & 4 & 0.4808 & & 0.5769 & 0.3654 & 0.5073 & & 0.6667 & 0.5362 \\
\hline & & 0.7815 & & 0.2673 & 0.0522 & 0.9042 & & 0.0056 & 0.5472 \\
\hline & 20 & 0.6389 & & 0.5556 & 0.5000 & 0.4151 & & 0.4528 & 0.4906 \\
\hline & & 0.0956 & & 0.5050 & 1.0000 & 0.2164 & & 0.4922 & 0.8908 \\
\hline \multicolumn{10}{|c|}{ Panel B: CAN\$/\$ } \\
\hline \multirow[t]{6}{*}{ ECM } & 1 & 0.4727 & 0.4286 & 0.4000 & 0.3818 & 0.5139 & 0.4247 & 0.5000 & 0.4583 \\
\hline & & 0.6858 & 0.2851 & 0.1380 & 0.0796 & 0.8137 & 0.1979 & 1.0000 & 0.4795 \\
\hline & 4 & 0.4423 & 0.3393 & 0.4231 & 0.3462 & 0.5362 & 0.3699 & 0.5942 & 0.3188 \\
\hline & & 0.4054 & 0.0162 & 0.2673 & 0.0265 & 0.5472 & 0.0262 & 0.1176 & 0.0026 \\
\hline & 20 & 0.5000 & 0.7321 & 0.4722 & 0.0833 & 0.4717 & 0.7671 & 0.5094 & 0.1509 \\
\hline & & 1.0000 & 0.0005 & 0.7389 & 0.0000 & 0.6803 & 0.0000 & 0.8908 & 0.0000 \\
\hline \multirow[t]{6}{*}{ FD } & 1 & 0.5091 & & 0.4727 & 0.6182 & 0.5417 & & 0.4444 & 0.6111 \\
\hline & & 0.8927 & & 0.6858 & 0.0796 & 0.4795 & & 0.3458 & 0.0593 \\
\hline & 4 & 0.5385 & & 0.5192 & 0.6731 & 0.4783 & & 0.4928 & 0.6232 \\
\hline & & 0.5791 & & 0.7815 & 0.0126 & 0.7180 & & 0.9042 & 0.0407 \\
\hline & 20 & 0.8889 & & 0.8889 & 0.5833 & 0.5849 & & 0.6038 & 0.5094 \\
\hline & & 0.0000 & & 0.0000 & 0.3173 & 0.2164 & & 0.1308 & 0.8908 \\
\hline \multicolumn{10}{|c|}{ Panel C: DM/\$ } \\
\hline \multirow[t]{6}{*}{ ECM } & 1 & 0.6364 & 0.3571 & 0.4546 & 0.4909 & 0.4861 & 0.4110 & 0.5000 & 0.4861 \\
\hline & & 0.0431 & 0.0325 & 0.5002 & 0.8927 & 0.8137 & 0.1281 & 1.0000 & 0.8137 \\
\hline & 4 & 0.6346 & 0.4286 & 0.4615 & 0.4615 & 0.4493 & 0.4247 & 0.4493 & 0.5073 \\
\hline & & 0.0522 & 0.2851 & 0.5791 & 0.5791 & 0.3994 & 0.1979 & 0.3994 & 0.9042 \\
\hline & 20 & 0.5833 & 0.6964 & 0.3333 & 0.3333 & 0.2830 & 0.5890 & 0.4340 & 0.5094 \\
\hline & & 0.3173 & 0.0033 & 0.0455 & 0.0455 & 0.0016 & 0.1281 & 0.3363 & 0.8908 \\
\hline \multirow[t]{6}{*}{ FD } & 1 & 0.4546 & & 0.4727 & 0.8000 & 0.4444 & & 0.4444 & 0.7500 \\
\hline & & 0.5002 & & 0.6858 & 0.0000 & 0.3458 & & 0.3458 & 0.0000 \\
\hline & 4 & 0.3654 & & 0.4615 & 0.6731 & 0.4928 & & 0.4493 & 0.6087 \\
\hline & & 0.0522 & & 0.5791 & 0.0126 & 0.9042 & & 0.3994 & 0.0710 \\
\hline & 20 & 0.6111 & & 0.6389 & 0.6667 & 0.5094 & & 0.4151 & 0.4717 \\
\hline & & 0.1824 & & 0.0956 & 0.0455 & 0.8908 & & 0.2164 & 0.6803 \\
\hline
\end{tabular}


Table 3: (Continued)

\begin{tabular}{|c|c|c|c|c|c|c|c|c|c|}
\hline \multirow[b]{2}{*}{ Specification } & \multirow[b]{2}{*}{ Horizon } & \multicolumn{4}{|c|}{ Sample 1: 1987 Q2 - 2000 Q4 } & \multicolumn{4}{|c|}{ Sample 2: 1983 Q1-2000 Q4 } \\
\hline & & S-P & IRP & PROD & BEER & S-P & IRP & PROD & BEER \\
\hline \multicolumn{10}{|l|}{ Panel D: SF/\$ } \\
\hline \multirow[t]{6}{*}{ ECM } & 1 & 0.4000 & 0.3393 & 0.6182 & . & 0.5417 & 0.3836 & 0.6250 & . \\
\hline & & 0.1380 & 0.0162 & 0.0796 & . & 0.4795 & 0.0466 & 0.0339 & \\
\hline & 4 & 0.4039 & 0.4107 & 0.5385 & . & 0.5797 & 0.4247 & 0.5797 & . \\
\hline & & 0.1655 & 0.1815 & 0.5791 & . & 0.1854 & 0.1979 & 0.1854 & . \\
\hline & 20 & 0.4444 & 0.4546 & 0.5833 & . & 0.5283 & 0.4546 & 0.4340 & . \\
\hline & & 0.5050 & 0.6698 & 0.3173 & . & 0.6803 & 0.6698 & 0.3363 & . \\
\hline \multirow[t]{6}{*}{ FD } & 1 & 0.4364 & & 0.4000 & . & 0.4444 & . & 0.4583 & . \\
\hline & & 0.3452 & & 0.1380 & . & 0.3458 & . & 0.4795 & . \\
\hline & 4 & 0.3462 & & 0.3077 & . & 0.4348 & . & 0.3623 & . \\
\hline & & 0.0265 & & 0.0055 & . & 0.2786 & . & 0.0222 & . \\
\hline & 20 & 0.6111 & & 0.6111 & . & 0.7170 & . & 0.6981 & . \\
\hline & & 0.1824 & & 0.1824 & . & 0.0016 & . & 0.0039 & . \\
\hline \multicolumn{10}{|c|}{ Panel E: Yen/\$ } \\
\hline \multirow[t]{6}{*}{ ECM } & 1 & 0.5273 & 0.3750 & 0.5455 & . & 0.5972 & 0.4247 & 0.5139 & . \\
\hline & & 0.6858 & 0.0614 & 0.5002 & . & 0.0990 & 0.1979 & 0.8137 & . \\
\hline & 4 & 0.5769 & 0.4821 & 0.5192 & . & 0.6232 & 0.5480 & 0.4058 & . \\
\hline & & 0.2673 & 0.7893 & 0.7815 & . & 0.0407 & 0.4126 & 0.1176 & . \\
\hline & 20 & 0.5556 & 0.6964 & 0.5556 & . & 0.4151 & 0.7031 & 0.3396 & . \\
\hline & & 0.5050 & 0.0033 & 0.5050 & . & 0.2164 & 0.0012 & 0.0195 & . \\
\hline \multirow[t]{6}{*}{ FD } & 1 & 0.5818 & & 0.5636 & . & 0.5833 & & 0.5417 & . \\
\hline & & 0.2249 & & 0.3452 & . & 0.1573 & & 0.4795 & . \\
\hline & 4 & 0.6539 & & 0.5962 & . & 0.6522 & & 0.6522 & . \\
\hline & & 0.0265 & & 0.1655 & . & 0.0115 & & 0.0115 & . \\
\hline & 20 & 0.6111 & & 0.5833 & . & 0.7547 & & 0.7359 & . \\
\hline & & 0.1824 & & 0.3173 & . & 0.0002 & & 0.0006 & \\
\hline
\end{tabular}

Note: Table 3 reports the proportion of forecasts that correctly predict the direction of the dollar exchange rate movement. Underneath each direction of change statistic, the $p$-values for the hypothesis that the reported proportion is significantly different from $1 / 2$ is listed. When the statistic is significantly larger than $1 / 2$, the forecast is said to have the ability to predict the direct of change. If the statistic is significantly less than $1 / 2$, the forecast tends to give the wrong direction of change. The notation used in the table is ECM: error correction specification; FD: first-difference specification; S-P: sticky-price model; IRP: interest rate parity model; PROD: productivity differential model; and BEER: behavioral equilibrium exchange rate model. The forecasting horizons (in quarters) are listed under the heading "Horizon." The results for the post-Louvre Accord forecasting period are given under the label "Sample 1" and those for the post-1983 forecasting period are given under the label "Sample 2." A "." indicates the statistics are not generated due to unavailability of data. 
Table 4: Direction of Change Statistics from the Yen-Based Exchange Rates

\begin{tabular}{|c|c|c|c|c|c|c|c|}
\hline \multirow{2}{*}{ Specification } & \multirow[b]{2}{*}{ Horizon } & \multicolumn{3}{|c|}{ Sample 1: 1987 Q2 - 2000 Q4 } & \multicolumn{3}{|c|}{ Sample 2: 1983 Q1-2000 Q4 } \\
\hline & & S-P & IRP & PROD & S-P & IRP & PROD \\
\hline \multicolumn{8}{|c|}{ Panel A: BP/Yen } \\
\hline \multirow[t]{6}{*}{$\mathrm{ECM}$} & 1 & 0.4546 & 0.4286 & 0.5091 & 0.3889 & 0.5069 & 0.4861 \\
\hline & & 0.5002 & 0.2851 & 0.8927 & 0.0593 & 0.9068 & 0.8137 \\
\hline & 4 & 0.5000 & 0.6429 & 0.5192 & 0.4058 & 0.7123 & 0.5073 \\
\hline & & 1.0000 & 0.0325 & 0.7815 & 0.1176 & 0.0003 & 0.9042 \\
\hline & 20 & 0.3611 & 0.7143 & 0.5278 & 0.6226 & 0.7500 & 0.5660 \\
\hline & & 0.0956 & 0.0013 & 0.7389 & 0.0742 & 0.0001 & 0.3363 \\
\hline \multirow[t]{6}{*}{ FD } & 1 & 0.5455 & & 0.5091 & 0.5278 & & 0.5417 \\
\hline & & 0.5002 & & 0.8927 & 0.6374 & & 0.4795 \\
\hline & 4 & 0.6346 & & 0.6346 & 0.6957 & & 0.7391 \\
\hline & & 0.0522 & & 0.0522 & 0.0012 & & 0.0001 \\
\hline & 20 & 0.6111 & & 0.6111 & 0.7170 & & 0.7170 \\
\hline & & 0.1824 & & 0.1824 & 0.0016 & & 0.0016 \\
\hline \multicolumn{8}{|c|}{ Panel B: CAN\$/Yen } \\
\hline \multirow[t]{6}{*}{ ECM } & 1 & 0.5455 & 0.5000 & 0.4364 & 0.5833 & 0.5343 & 0.5278 \\
\hline & & 0.5002 & 1.0000 & 0.3452 & 0.1573 & 0.5584 & 0.6374 \\
\hline & 4 & 0.4808 & 0.5893 & 0.4615 & 0.5797 & 0.6438 & 0.5362 \\
\hline & & 0.7815 & 0.1815 & 0.5791 & 0.1854 & 0.0140 & 0.5472 \\
\hline & 20 & 0.4167 & 0.7679 & 0.4444 & 0.4528 & 0.7969 & 0.5283 \\
\hline & & 0.3173 & 0.0001 & 0.5050 & 0.4922 & 0.0000 & 0.6803 \\
\hline \multirow[t]{6}{*}{ FD } & 1 & 0.5091 & & 0.5091 & 0.4722 & & 0.5000 \\
\hline & & 0.8927 & & 0.8927 & 0.6374 & & 1.0000 \\
\hline & 4 & 0.5385 & & 0.5769 & 0.6377 & & 0.6232 \\
\hline & & 0.5791 & & 0.2673 & 0.0222 & & 0.0407 \\
\hline & 20 & 0.6944 & & 0.6944 & 0.7359 & & 0.7170 \\
\hline & & 0.0196 & & 0.0196 & 0.0006 & & 0.0016 \\
\hline \multicolumn{8}{|c|}{ Panel C: US\$/Yen } \\
\hline \multirow[t]{6}{*}{ ECM } & 1 & 0.5273 & 0.3750 & 0.5455 & 0.5972 & 0.4247 & 0.5139 \\
\hline & & 0.6858 & 0.0614 & 0.5002 & 0.0990 & 0.1979 & 0.8137 \\
\hline & 4 & 0.5769 & 0.4821 & 0.5192 & 0.6232 & 0.5480 & 0.4058 \\
\hline & & 0.2673 & 0.7893 & 0.7815 & 0.0407 & 0.4126 & 0.1176 \\
\hline & 20 & 0.5556 & 0.6964 & 0.5556 & 0.4151 & 0.7031 & 0.3396 \\
\hline & & 0.5050 & 0.0033 & 0.5050 & 0.2164 & 0.0012 & 0.0195 \\
\hline \multirow[t]{6}{*}{ FD } & 1 & 0.5818 & & 0.5636 & 0.5833 & & 0.5417 \\
\hline & & 0.2249 & & 0.3452 & 0.1573 & & 0.4795 \\
\hline & 4 & 0.6539 & & 0.5962 & 0.6522 & & 0.6522 \\
\hline & & 0.0265 & & 0.1655 & 0.0115 & & 0.0115 \\
\hline & 20 & 0.6111 & & 0.5833 & 0.7547 & & 0.7359 \\
\hline & & 0.1824 & & 0.3173 & 0.0002 & & 0.0006 \\
\hline
\end{tabular}


Table 4: (Continued)

\begin{tabular}{|c|c|c|c|c|c|c|c|}
\hline \multirow[b]{2}{*}{ Specification } & \multirow[b]{2}{*}{ Horizon } & \multicolumn{3}{|c|}{ Sample 1: 1987 Q2 - 2000 Q4 } & \multicolumn{3}{|c|}{$\begin{array}{l}\text { Sample 2: } 1983 \text { Q1-2000 } \\
\text { Q4 }\end{array}$} \\
\hline & & S-P & IRP & PROD & S-P & IRP & PROD \\
\hline \multicolumn{8}{|c|}{ Panel D: DM/Yen } \\
\hline \multirow[t]{6}{*}{ ECM } & 1 & 0.6000 & 0.4464 & 0.6546 & 0.4306 & 0.4247 & 0.6111 \\
\hline & & 0.1380 & 0.4227 & 0.0219 & 0.2386 & 0.1979 & 0.0593 \\
\hline & 4 & 0.4615 & 0.5357 & 0.4808 & 0.5073 & 0.5206 & 0.5217 \\
\hline & & 0.5791 & 0.5930 & 0.7815 & 0.9042 & 0.7255 & 0.7180 \\
\hline & 20 & 0.4444 & 0.7143 & 0.5556 & 0.5283 & 0.7188 & 0.6226 \\
\hline & & 0.5050 & 0.0013 & 0.5050 & 0.6803 & 0.0005 & 0.0742 \\
\hline \multirow[t]{6}{*}{ FD } & 1 & 0.4546 & & 0.5091 & 0.4861 & & 0.5139 \\
\hline & & 0.5002 & & 0.8927 & 0.8137 & & 0.8137 \\
\hline & 4 & 0.4039 & & 0.4808 & 0.4928 & & 0.5362 \\
\hline & & 0.1655 & & 0.7815 & 0.9042 & & 0.5472 \\
\hline & 20 & 0.6111 & & 0.6111 & 0.5660 & & 0.4528 \\
\hline & & 0.1824 & & 0.1824 & 0.3363 & & 0.4922 \\
\hline \multicolumn{8}{|c|}{ Panel E: SF/Yen } \\
\hline \multirow[t]{6}{*}{$\mathrm{ECM}$} & 1 & 0.6182 & 0.5179 & 0.4182 & 0.5972 & 0.4384 & 0.5139 \\
\hline & & 0.0796 & 0.7893 & 0.2249 & 0.0990 & 0.2922 & 0.8137 \\
\hline & 4 & 0.5192 & 0.4643 & 0.3077 & 0.4783 & 0.3973 & 0.4493 \\
\hline & & 0.7815 & 0.5930 & 0.0055 & 0.7180 & 0.0792 & 0.3994 \\
\hline & 20 & 0.5278 & 0.5000 & 0.5000 & 0.3962 & 0.5000 & 0.3396 \\
\hline & & 0.7389 & 1.0000 & 1.0000 & 0.1308 & 1.0000 & 0.0195 \\
\hline \multirow[t]{6}{*}{ FD } & 1 & 0.4727 & & 0.4909 & 0.4722 & & 0.5000 \\
\hline & & 0.6858 & & 0.8927 & 0.6374 & & 1.0000 \\
\hline & 4 & 0.4615 & & 0.5192 & 0.5217 & & 0.4493 \\
\hline & & 0.5791 & & 0.7815 & 0.7180 & & 0.3994 \\
\hline & 20 & 0.6944 & & 0.6944 & 0.6038 & & 0.4906 \\
\hline & & 0.0196 & & 0.0196 & 0.1308 & & 0.8908 \\
\hline
\end{tabular}

Note: Table 4 reports the proportion of forecasts that correctly predict the direction of the yen-based exchange rate movement. Underneath each direction of change statistic, the $p$-values for the hypothesis that the reported proportion is significantly different from $1 / 2$ is listed. When the statistic is significantly larger than $1 / 2$, the forecast is said to have the ability to predict the direct of change. If the statistic is significantly less than $1 / 2$, the forecast tends to give the wrong direction of change. The notation used in the table is ECM: error correction specification; FD: first-difference specification; S-P: sticky-price model; IRP: interest rate parity model; PROD: productivity differential model; and BEER: behavioral equilibrium exchange rate model. The forecasting horizons (in quarters) are listed under the heading "Horizon." The results for the post-Louvre Accord forecasting period are given under the label "Sample 1 " and those for the post-1983 forecasting period are given under the label "Sample 2." 
Table 5: Cointegration between Dollar-Based Exchange Rates and their Forecasts

\begin{tabular}{|c|c|c|c|c|c|c|c|c|c|}
\hline \multirow[b]{2}{*}{ Specification } & \multirow[b]{2}{*}{ Horizon } & \multicolumn{4}{|c|}{ Sample 1: 1987 Q2 - 2000 Q4 } & \multicolumn{4}{|c|}{ Sample 2: 1983 Q1-2000 Q4 } \\
\hline & & $\mathrm{S}-\mathrm{P}$ & IRP & PROD & BEER & $\mathrm{S}-\mathrm{P}$ & IRP & PROD & BEER \\
\hline \multicolumn{10}{|c|}{ Panel A: BP/S } \\
\hline \multirow[t]{3}{*}{$\mathrm{ECM}$} & 1 & 7.26 & 0.77 & 6.95 & $12.64 *$ & $17.09^{*}$ & 4.60 & $10.40^{*}$ & $32.83 *$ \\
\hline & 4 & 8.56 & 1.47 & $9.66^{*}$ & $84.86^{*}$ & $12.98 *$ & 3.77 & 7.88 & $18.94 *$ \\
\hline & 20 & $15.84 *$ & 5.30 & $18.82 *$ & 6.95 & 3.16 & 5.03 & 4.25 & 4.72 \\
\hline \multirow[t]{3}{*}{ FD } & 1 & $25.63 *$ & & $20.85^{*}$ & $13.03 *$ & $34.00 *$ & & 8.60 & $16.91 *$ \\
\hline & 4 & 7.30 & & 6.71 & 2.21 & 6.98 & & 3.02 & 3.45 \\
\hline & 20 & 8.45 & & $13.00 *$ & 3.44 & 3.57 & & 2.79 & 2.24 \\
\hline \multicolumn{10}{|c|}{ Panel B: CANS/US\$ } \\
\hline \multirow[t]{3}{*}{$\mathrm{ECM}$} & 1 & $11.64 *$ & 1.29 & 4.37 & $10.35^{*}$ & $14.31 *$ & 1.90 & $13.96^{*}$ & $19.66^{*}$ \\
\hline & 4 & $10.27 *$ & 2.53 & 4.55 & 5.39 & 6.37 & 1.53 & $9.58 *$ & $13.52 *$ \\
\hline & 20 & $15.02 *$ & 3.98 & $19.82 *$ & $9.67 *$ & 2.61 & 4.18 & 1.60 & 2.19 \\
\hline \multirow[t]{3}{*}{ FD } & 1 & $26.34 *$ & & $31.53^{*}$ & 9.19 & $25.72 *$ & & $9.89 *$ & 8.12 \\
\hline & 4 & 3.19 & & 3.87 & 3.88 & 6.99 & & 8.63 & 3.89 \\
\hline & 20 & $10.03 *$ & & $9.59 *$ & 6.72 & 1.45 & & 2.21 & 3.52 \\
\hline \multicolumn{10}{|c|}{ Panel C: DM/\$ } \\
\hline \multirow[t]{3}{*}{$\mathrm{ECM}$} & 1 & 3.67 & 5.19 & 3.86 & 5.23 & $12.68 *$ & 2.84 & $27.29 *$ & $21.03 *$ \\
\hline & 4 & 5.24 & 2.74 & 5.37 & $18.33^{*}$ & $24.06^{*}$ & 1.81 & 6.67 & 8.49 \\
\hline & 20 & 6.09 & 1.63 & 7.55 & 9.20 & 3.56 & 2.37 & 2.94 & $16.60 *$ \\
\hline \multirow[t]{3}{*}{ FD } & 1 & $20.82 *$ & & 4.02 & 8.29 & $36.32 *$ & & $35.91 *$ & 2.18 \\
\hline & 4 & 4.27 & & 3.16 & $15.29 *$ & 7.56 & & $10.82 *$ & 2.80 \\
\hline & 20 & 5.42 & & 8.62 & 3.74 & 3.69 & & 4.16 & 4.26 \\
\hline \multicolumn{10}{|c|}{ Panel D: SF/\$ } \\
\hline \multirow[t]{3}{*}{$\mathrm{ECM}$} & 1 & 6.75 & 3.45 & 3.80 & . & $22.10 *$ & 3.23 & 6.33 & . \\
\hline & 4 & 8.55 & 2.07 & 9.10 & . & $10.71 *$ & 2.27 & $9.68^{*}$ & . \\
\hline & 20 & 1.16 & 6.93 & 1.81 & . & 2.93 & 6.93 & 2.96 & . \\
\hline \multirow[t]{3}{*}{ FD } & 1 & $33.01 *$ & & $20.30 *$ & . & $23.55^{*}$ & & $10.38^{*}$ & . \\
\hline & 4 & $10.96^{*}$ & & 6.71 & . & $14.33^{*}$ & & $13.74 *$ & . \\
\hline & 20 & 9.43 & & 7.51 & . & 2.27 & & 2.59 & . \\
\hline \multicolumn{10}{|c|}{ Panel E: Yen/\$ } \\
\hline \multirow[t]{3}{*}{$\mathrm{ECM}$} & 1 & 2.19 & 6.94 & 1.84 & . & $19.44^{*}$ & 6.45 & $12.73 *$ & . \\
\hline & 4 & 3.43 & 4.13 & 3.22 & . & $10.71 *$ & 3.27 & $14.79 *$ & . \\
\hline & 20 & 4.67 & 2.93 & 2.19 & . & 2.90 & 3.48 & 5.63 & . \\
\hline \multirow[t]{3}{*}{ FD } & 1 & $13.35^{*}$ & & $9.79 *$ & . & $15.47 *$ & & $15.47^{*}$ & . \\
\hline & 4 & 5.53 & & 3.77 & . & 6.02 & & 5.74 & . \\
\hline & 20 & 1.76 & & 2.15 & . & 4.94 & & 3.96 & . \\
\hline
\end{tabular}


Note: The Johansen maximum eigenvalue statistic for the null hypothesis that a dollar-based exchange rate and its forecast are no cointegrated. "*" indicates $10 \%$ level significance. Tests for the null of one cointegrating vector were also conducted but in all cases the null was not rejected. The notation used in the table is ECM: error correction specification; FD: first-difference specification; S-P: sticky-price model; IRP: interest rate parity model; PROD: productivity differential model; and BEER: behavioral equilibrium exchange rate model. The forecasting horizons (in quarters) are listed under the heading "Horizon." The results for the post-Louvre Accord forecasting period are given under the label "Sample 1 " and those for the post-1983 forecasting period are given under the label "Sample 2." A "." indicates the statistics are not generated due to unavailability of data. 
Table 6: Cointegration between Yen-Based Exchange Rates and their Forecasts

\begin{tabular}{|c|c|c|c|c|c|c|c|}
\hline \multirow[b]{2}{*}{ Specification } & \multirow[b]{2}{*}{ Horizon } & \multicolumn{3}{|c|}{ Sample 1: 1987 Q2 - 2000 Q4 } & \multicolumn{3}{|c|}{ Sample 2: 1983 Q1-2000 Q4 } \\
\hline & & S-P & IRP & PROD & S-P & IRP & PROD \\
\hline \multicolumn{8}{|c|}{ Panel A: BP/Yen } \\
\hline \multirow[t]{3}{*}{$\mathrm{ECM}$} & 1 & 2.60 & $9.79 *$ & 3.53 & 8.63 & $11.05^{*}$ & 4.06 \\
\hline & 4 & 2.68 & 7.66 & 1.92 & 8.72 & $9.79 *$ & 6.30 \\
\hline & 20 & 3.88 & 5.71 & 4.29 & 8.33 & 3.32 & $9.55^{*}$ \\
\hline \multirow[t]{3}{*}{ FD } & 1 & $38.24 *$ & & $46.93 *$ & $43.12 *$ & & $43.65^{*}$ \\
\hline & 4 & $13.81 *$ & & $13.23 *$ & $13.50 *$ & & $17.52 *$ \\
\hline & 20 & 2.32 & & 2.25 & 3.47 & & 3.83 \\
\hline \multicolumn{8}{|c|}{ Panel B: CAN\$/Yen } \\
\hline \multirow[t]{3}{*}{ ECM } & 1 & 7.66 & $10.07 *$ & $12.62 *$ & $16.52^{*}$ & $15.42 *$ & $15.32 *$ \\
\hline & 4 & 7.55 & $10.29 *$ & 9.31 & $11.40 *$ & $11.11^{*}$ & $40.72 *$ \\
\hline & 20 & 2.81 & $11.04 *$ & 4.50 & 5.36 & $11.97 *$ & 4.61 \\
\hline \multirow[t]{3}{*}{ FD } & 1 & $31.03 *$ & . & $32.75^{*}$ & $21.00^{*}$ & & $38.87 *$ \\
\hline & 4 & 5.14 & . & 5.05 & 6.86 & & 5.38 \\
\hline & 20 & 6.20 & . & 2.72 & 3.60 & & 5.29 \\
\hline \multicolumn{8}{|c|}{ Panel C: US\$/Yen } \\
\hline \multirow[t]{3}{*}{$\mathrm{ECM}$} & 1 & 2.19 & 6.94 & 1.84 & $19.44^{*}$ & 6.45 & $12.73 *$ \\
\hline & 4 & 3.43 & 4.13 & 3.22 & $10.71 *$ & 3.27 & $14.79 *$ \\
\hline & 20 & 4.67 & 2.93 & 2.19 & 2.90 & 3.48 & 5.63 \\
\hline \multirow[t]{3}{*}{ FD } & 1 & $13.35^{*}$ & & $9.79 *$ & $15.47 *$ & & $15.47 *$ \\
\hline & 4 & 5.53 & & 3.77 & 6.02 & & 5.74 \\
\hline & 20 & 1.76 & & 2.15 & 4.94 & & 3.96 \\
\hline \multicolumn{8}{|c|}{ Panel D: DM/Yen } \\
\hline \multirow[t]{3}{*}{ ECM } & 1 & $25.38 *$ & 6.64 & $27.61^{*}$ & $32.48^{*}$ & 2.62 & $31.34 *$ \\
\hline & 4 & $14.29 *$ & 5.43 & $11.08^{*}$ & $14.18^{*}$ & 2.24 & $13.96^{*}$ \\
\hline & 20 & 13.99 & 7.60 & 5.39 & $16.07^{*}$ & 8.82 & $16.79 *$ \\
\hline \multirow[t]{3}{*}{ FD } & 1 & $23.07 *$ & & $28.73 *$ & $37.69^{*}$ & & $17.57 *$ \\
\hline & 4 & $15.19 *$ & & $11.27^{*}$ & 5.91 & & 4.63 \\
\hline & 20 & $19.61 *$ & & $19.21 *$ & 4.82 & & 4.75 \\
\hline \multicolumn{8}{|c|}{ Panel E: SF/Yen } \\
\hline \multirow[t]{3}{*}{$\mathrm{ECM}$} & 1 & $7.50 *$ & $20.19 *$ & $13.16^{*}$ & $26.65^{*}$ & 5.46 & $22.58 *$ \\
\hline & 4 & 4.36 & 4.39 & 7.72 & $115.2 *$ & 2.81 & 9.02 \\
\hline & 20 & 5.02 & 4.72 & 5.87 & 6.58 & 4.72 & 6.16 \\
\hline \multirow[t]{3}{*}{ FD } & 1 & $45.52 *$ & & $48.77^{*}$ & $50.81 *$ & & $55.40 *$ \\
\hline & 4 & $9.69^{*}$ & & $10.98^{*}$ & 10.99 & & $11.72 *$ \\
\hline & 20 & 4.55 & & 4.80 & 6.21 & & 5.60 \\
\hline
\end{tabular}


Note: The Johansen maximum eigenvalue statistic for the null hypothesis that a yen-based exchange rate and its forecast are no cointegrated. "*" indicates $10 \%$ level significance. Tests for the null of one cointegrating vector were also conducted but in all cases the null was not rejected. The notation used in the table is ECM: error correction specification; FD: first-difference specification; S-P: sticky-price model; IRP: interest rate parity model; PROD: productivity differential model; and BEER: behavioral equilibrium exchange rate model. The forecasting horizons (in quarters) are listed under the heading "Horizon." The results for the post-Louvre Accord forecasting period are given under the label "Sample 1 " and those for the post-1983 forecasting period are given under the label "Sample 2." 
Table 7: Results of the $(1,-1)$ Restriction Test: Dollar-Based Exchange Rates

\begin{tabular}{|c|c|c|c|c|c|c|c|c|c|}
\hline \multirow[b]{2}{*}{ Specification } & \multirow[b]{2}{*}{ Horizon } & \multicolumn{4}{|c|}{ Sample 1: 1987 Q2 - 2000 Q4 } & \multicolumn{4}{|c|}{ Sample 2: 1983 Q1-2000 Q4 } \\
\hline & & S-P & IRP & PROD & BEER & S-P & IRP & PROD & BEER \\
\hline \multicolumn{10}{|l|}{ Panel A: BP/\$ } \\
\hline \multirow[t]{6}{*}{ ECM } & 1 & & & & 0.55 & 3.38 & & 0.00 & 0.35 \\
\hline & & & & & 0.46 & 0.07 & & 1.00 & 0.56 \\
\hline & 4 & & & 0.98 & 1.02 & 2.59 & & & 0.09 \\
\hline & & & & 0.32 & 0.31 & 0.11 & & & 0.76 \\
\hline & 20 & 0.40 & & 0.36 & & & & & \\
\hline & & 0.53 & & 0.55 & & & & & \\
\hline \multirow[t]{5}{*}{ FD } & 1 & 5.38 & & 0.12 & 0.04 & 0.79 & & & 0.36 \\
\hline & & 0.02 & & 0.73 & 0.83 & 0.38 & & & 0.55 \\
\hline & 4 & & & & & & & & \\
\hline & 20 & & & 23.20 & & & & & \\
\hline & & & & 0.00 & & & & & \\
\hline \multicolumn{10}{|c|}{ Panel B: CAN\$/\$ } \\
\hline \multirow[t]{6}{*}{ ECM } & 1 & 11.20 & & & 4.46 & 7.75 & & 2.87 & 6.48 \\
\hline & & 0.00 & & & 0.03 & 0.01 & & 0.09 & 0.01 \\
\hline & 4 & 24.05 & & & & & & 5.36 & 4.52 \\
\hline & & 0.00 & & & & & & 0.02 & 0.03 \\
\hline & 20 & 76.59 & & 82.26 & 201.37 & & & & \\
\hline & & 0.00 & & 0.00 & 0.00 & & & & \\
\hline \multirow[t]{5}{*}{ FD } & 1 & 7.81 & & 6.09 & & 13.90 & & 5.47 & \\
\hline & & 0.01 & & 0.01 & & 0.00 & & 0.02 & \\
\hline & 4 & & & & & & & & \\
\hline & 20 & 4.39 & & 3.50 & & & & & \\
\hline & & 0.04 & & 0.06 & & & & & \\
\hline \multicolumn{10}{|c|}{ Panel C: DM/\$ } \\
\hline \multirow[t]{6}{*}{ ECM } & 1 & & & & & 8.82 & & 8.35 & 6.61 \\
\hline & & & & & & 0.00 & & 0.00 & 0.01 \\
\hline & 4 & & & & 3.20 & 6.31 & & & \\
\hline & & & & & 0.07 & 0.01 & & & \\
\hline & 20 & & & & & & & & 27.81 \\
\hline & & & & & & & & & 0.00 \\
\hline \multirow[t]{4}{*}{ FD } & 1 & 10.17 & & & & 3.03 & & 0.47 & \\
\hline & & 0.00 & & & & 0.08 & & 0.49 & \\
\hline & 4 & & & & 25.21 & & & 7.39 & \\
\hline & & & & & 0.00 & & & 0.01 & \\
\hline
\end{tabular}


Table 7: (Continued)

\begin{tabular}{|c|c|c|c|c|c|c|c|c|c|}
\hline \multirow[b]{2}{*}{ Specification } & \multirow[b]{2}{*}{ Horizon } & \multicolumn{4}{|c|}{ Sample 1: 1987 Q2 - 2000 Q4 } & \multicolumn{4}{|c|}{ Sample 2: 1983 Q1-2000 Q4 } \\
\hline & & S-P & IRP & PROD & BEER & S-P & IRP & PROD & BEER \\
\hline \multicolumn{10}{|c|}{ Panel D: SF/\$ } \\
\hline \multirow[t]{6}{*}{ ECM } & 1 & & & & . & 10.07 & & & . \\
\hline & & & & & . & 0.00 & & & . \\
\hline & 4 & & & & . & 2.40 & & 10.96 & . \\
\hline & & & & & . & 0.12 & & 0.00 & . \\
\hline & 20 & & & & . & & & & . \\
\hline & & & & & . & & & & . \\
\hline \multirow[t]{6}{*}{ FD } & 1 & 20.17 & & 20.82 & . & 4.57 & & 4.79 & . \\
\hline & & 0.00 & & 0.00 & . & 0.03 & & 0.03 & . \\
\hline & 4 & 20.87 & & & . & 8.84 & & 8.40 & . \\
\hline & & 0.00 & & & . & 0.00 & & 0.00 & . \\
\hline & 20 & & & & . & & & & . \\
\hline & & & & & . & & & & - \\
\hline \multicolumn{10}{|c|}{ Panel E: Yen/\$ } \\
\hline \multirow[t]{6}{*}{ ECM } & 1 & & & & . & 3.22 & & 2.47 & . \\
\hline & & & & & . & 0.07 & & 0.12 & . \\
\hline & 4 & & & & . & 0.55 & & 5.71 & . \\
\hline & & & & & . & 0.46 & & 0.02 & . \\
\hline & 20 & & & & . & & & & . \\
\hline & & & & & . & & & & . \\
\hline \multirow[t]{5}{*}{ FD } & 1 & 6.76 & & 5.40 & . & 0.45 & & 0.71 & . \\
\hline & & 0.01 & & 0.02 & . & 0.50 & & 0.40 & . \\
\hline & 4 & & & & . & & & & . \\
\hline & & & & & - & & & & - \\
\hline & 20 & & & & . & & & & . \\
\hline
\end{tabular}

Note: The likelihood ratio test statistic for the restriction of $(1,-1)$ on the cointegrating vector and its $\mathrm{p}$ value are reported. The test is only applied to the cointegration cases present in Table 5 . The notation used in the table is ECM: error correction specification; FD: first-difference specification; S-P: stickyprice model; IRP: interest rate parity model; PROD: productivity differential model; and BEER:

behavioral equilibrium exchange rate model. The forecasting horizons (in quarters) are listed under the heading "Horizon." The results for the post-Louvre Accord forecasting period are given under the label "Sample 1" and those for the post -1983 forecasting period are given under the label "Sample 2." A "." indicates the statistics are not generated due to unavailability of data. 
Table 8: Results of the $(1,-1)$ Restriction Test: Yen-Based Exchange Rates

\begin{tabular}{|c|c|c|c|c|c|c|c|}
\hline \multirow[b]{2}{*}{ Specification } & \multirow[b]{2}{*}{ Horizon } & \multicolumn{3}{|c|}{ Sample 1: 1987 Q2 - 2000 Q4 } & \multicolumn{3}{|c|}{ Sample 2: 1993 Q1-2000 Q4 } \\
\hline & & S-P & IRP & PROD & S-P & IRP & PROD \\
\hline \multicolumn{8}{|c|}{ Panel A: BP/Yen } \\
\hline \multirow[t]{4}{*}{ ECM } & 1 & & $\begin{array}{r}324.33 \\
0.00\end{array}$ & & & $\begin{array}{r}680.12 \\
0.00\end{array}$ & \\
\hline & 4 & & & & & 42917 & \\
\hline & 20 & & & & & 0.00 & 0.75 \\
\hline & & & & & & & 0.39 \\
\hline \multirow[t]{4}{*}{ FD } & 1 & 91.42 & & 144.90 & 31.95 & & 30.30 \\
\hline & & 0.00 & & 0.00 & 0.00 & & 0.00 \\
\hline & 4 & 140.97 & & 213.53 & 31.58 & & 42.83 \\
\hline & & 0.00 & & 0.00 & 0.00 & & 0.00 \\
\hline
\end{tabular}

\section{Panel B: CAN\$/Yen} ECM

1

4

20

FD

1

4

20

Panel C: US\$/Yen

ECM

\section{1}

4

20

FD

1

4

46.54

0.00

$\begin{array}{rr}2425 & 8.12 \\ 0.00 & 0.00 \\ 1319 & \\ 0.00 & \\ 9.16 & \\ 0.00 & \end{array}$

80.01

0.00

14.13

0.00

0.05

0.83

0.83

0.36

31517

0.81

$\begin{array}{ll}0.00 & 0.37\end{array}$

$\begin{array}{ll}1117 & 8.22\end{array}$

$0.00 \quad 0.00$

16.07

0.00

29.19

0.00

3.22

2.47

0.07

0.12

0.55

5.71

0.46

0.02

1

6.76

5.40

0.45

0.71

0.01

0.02

0.50

0.40 
Table 8: (Continued)

\begin{tabular}{|c|c|c|c|c|c|c|}
\hline \multirow[b]{2}{*}{ Specification } & \multirow[b]{2}{*}{ Horizon } & \multicolumn{3}{|c|}{ Sample 1: 1987 Q2 - 2000 Q4 } & \multicolumn{2}{|c|}{ Sample 2: 1983 Q1-2000 Q4 } \\
\hline & & S-P & IRP & PROD & S-P & PROD \\
\hline \multicolumn{7}{|c|}{ Panel D: DM/Yen } \\
\hline \multirow{6}{*}{ ECM } & 1 & 0.01 & & 0.06 & 0.51 & 0.36 \\
\hline & & 0.93 & & 0.80 & 0.47 & 0.54 \\
\hline & 4 & 1.12 & & 0.97 & 0.51 & 0.55 \\
\hline & & 0.29 & & 0.32 & 0.47 & 0.45 \\
\hline & 20 & & & & 0.01 & 0.81 \\
\hline & & & & & 0.91 & 0.36 \\
\hline \multirow[t]{6}{*}{ FD } & 1 & 2.67 & & 4.90 & 13.80 & 7.02 \\
\hline & & 0.10 & & 0.03 & 0.00 & 0.00 \\
\hline & 4 & 4.84 & & 6.87 & & \\
\hline & & 0.03 & & 0.00 & & \\
\hline & 20 & 24.04 & & 19.86 & & \\
\hline & & 0.00 & & 0.00 & & \\
\hline \multicolumn{7}{|c|}{ Panel E: SF/Yen } \\
\hline \multirow[t]{5}{*}{ ECM } & 1 & 22.56 & 94.44 & 0.50 & 11.59 & 4.53 \\
\hline & & 0.00 & 0.00 & 0.48 & 0.00 & 0.03 \\
\hline & 4 & & & & 85.62 & \\
\hline & & & & & 0.00 & \\
\hline & 20 & & & & & \\
\hline \multirow[t]{5}{*}{ FD } & 1 & 6.85 & & 5.82 & 4.16 & 3.82 \\
\hline & & 0.01 & & 0.02 & 0.04 & 0.05 \\
\hline & 4 & 14.41 & & 11.31 & & 2.29 \\
\hline & & 0.00 & & 0.00 & & 0.13 \\
\hline & 20 & & & & & \\
\hline
\end{tabular}

Note: Note: The likelihood ratio test statistic for the restriction of $(1,-1)$ on the cointegrating vector and its $p$-value are reported. The test is only applied to the cointegration cases present in Table 6 . The notation used in the table is ECM: error correction specification; FD: first-difference specification; S-P: stickyprice model; IRP: interest rate parity model; PROD: productivity differential model; and BEER:

behavioral equilibrium exchange rate model. The forecasting horizons (in quarters) are listed under the heading "Horizon." The results for the post-Louvre Accord forecasting period are given under the label "Sample 1" and those for the post-1983 forecasting period are given under the label "Sample 2." 


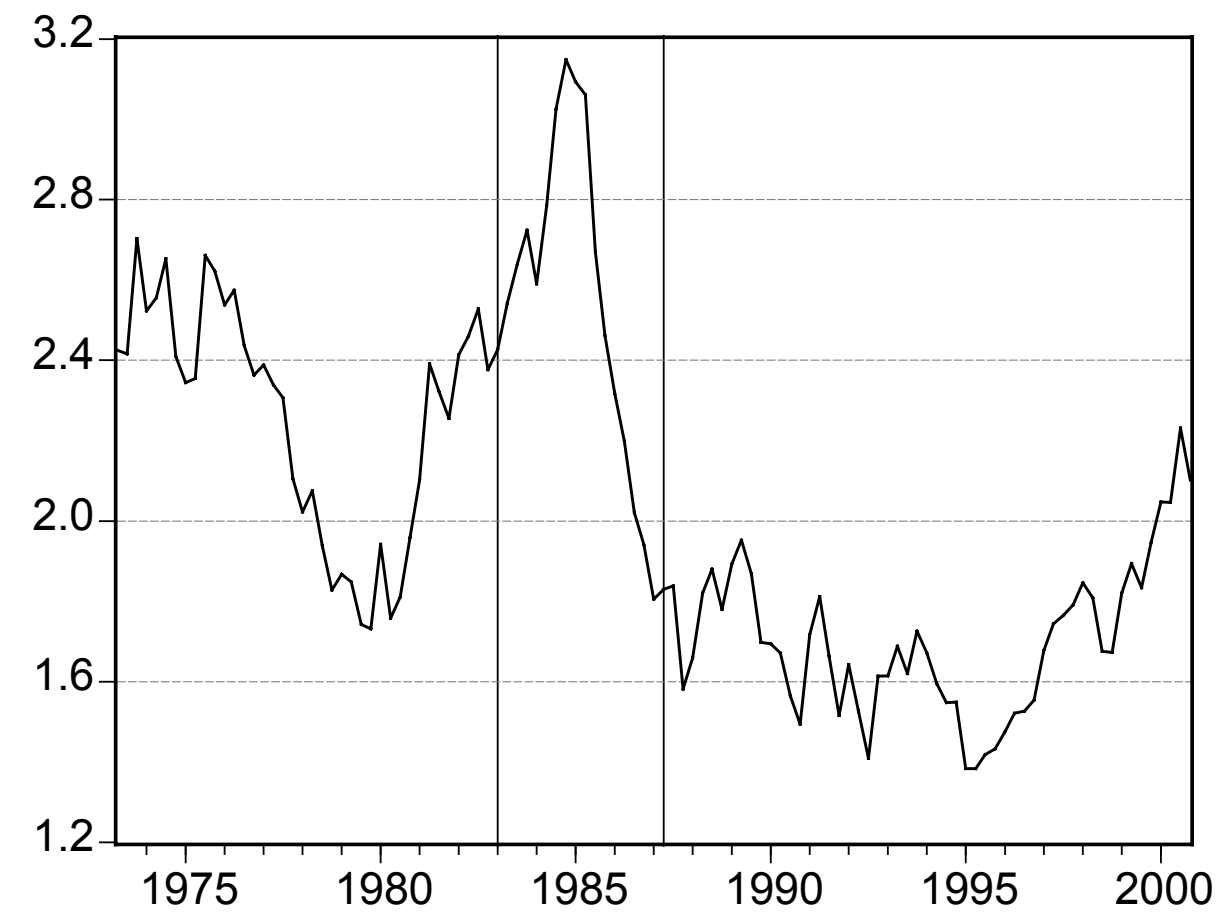

Figure 1: Deutsche Mark / US dollar exchange rate.

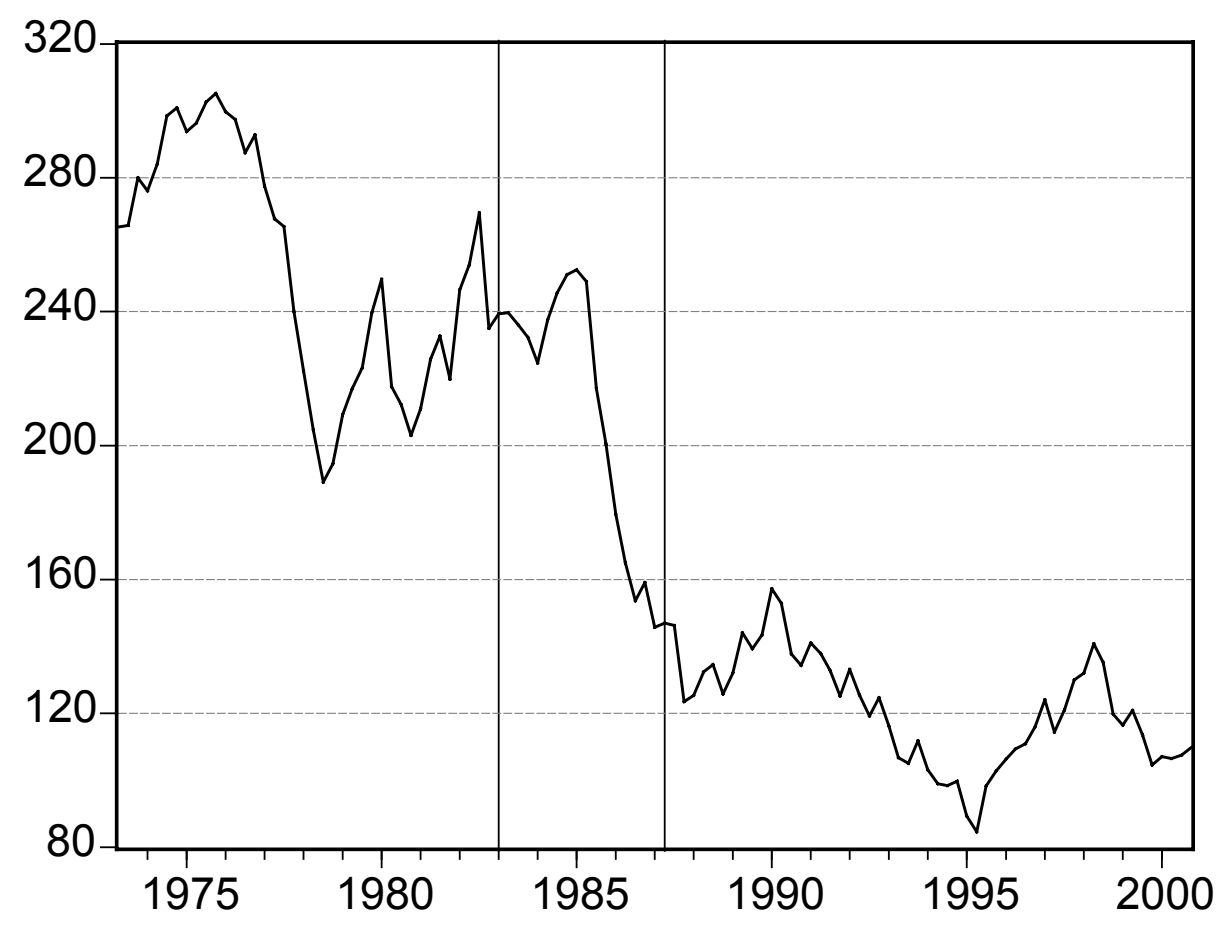

Figure 2: Japanese Yen / US dollar exchange rate. 


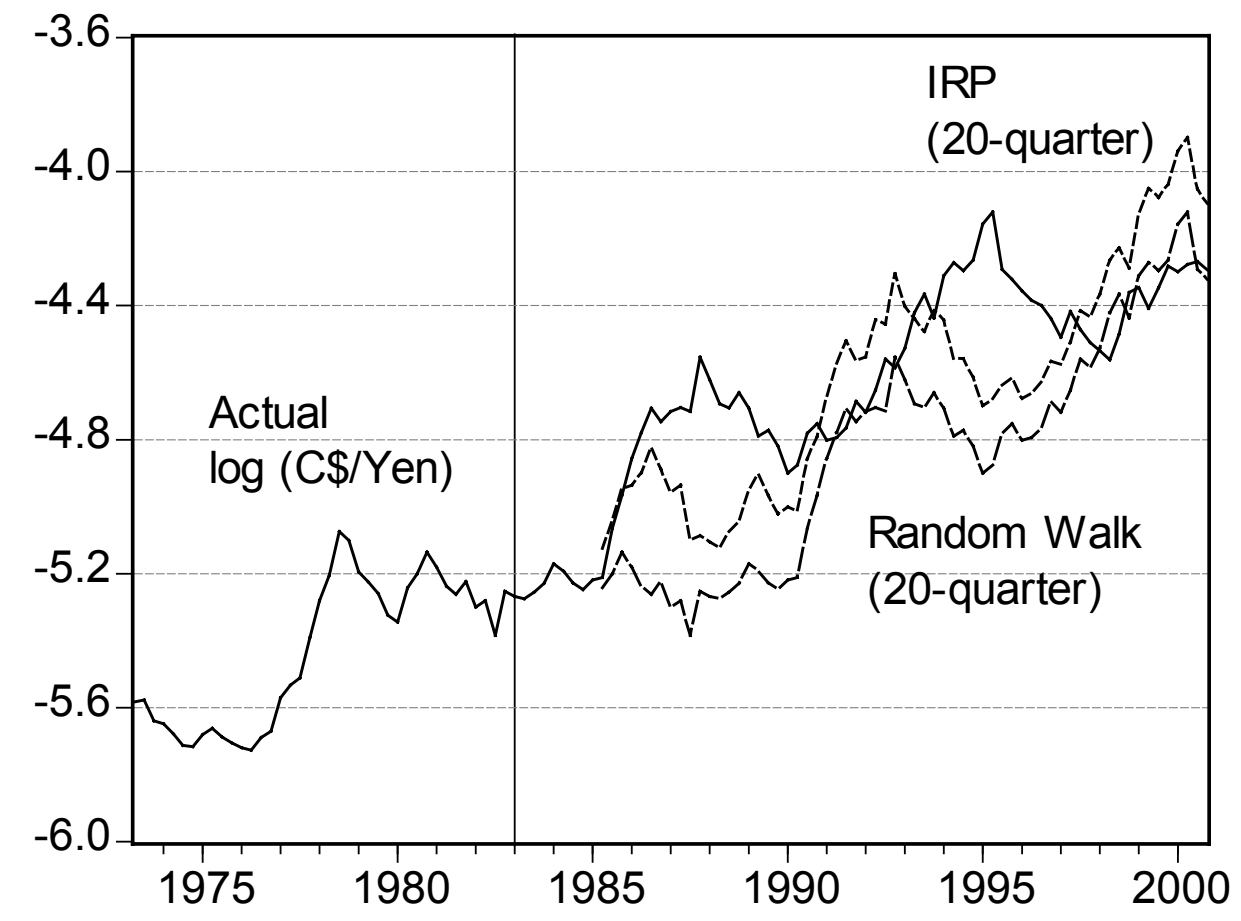

Figure 3: Canadian dollar / Yen actual, 20-quarter ahead interest rate parity and random walk forecasts. 